\title{
Virus-Like Particle-Induced Protection Against MRSA Pneumonia Is Dependent on IL-13 and Enhancement of Phagocyte Function
}

\author{
Agnieszka Rynda-Apple, ${ }^{*}$ Erin Dobrinen, ${ }^{*}$ \\ Mark McAlpine, ${ }^{*}$ Amanda Read, ${ }^{*}$ Ann Harmsen, ${ }^{*}$ \\ Laura E. Richert, ${ }^{*}$ Matthew Calverley, ${ }^{*}$ \\ Kyler Pallister, ${ }^{*}$ Jovanka Voyich, ${ }^{*}$ \\ James A. Wiley, ${ }^{*}$ Ben Johnson, ${ }^{\dagger}$ Mark Young, ${ }^{\ddagger}$ \\ Trevor Douglas, ${ }^{\dagger}$ and Allen G. Harmsen* \\ From the Departments of Immunology and Infectious Diseases, \\ Chemistry and Biochemistry, ${ }^{\dagger}$ and Plant Sciences and Plant \\ Pathology, ${ }^{\ddagger}$ Montana State University, Bozeman, Montana
}

The importance of the priming of the lung environment by past infections is being increasingly recognized. Exposure to any given antigen can either improve or worsen the outcome of subsequent lung infections, depending on the immunological history of the host. Thus, an ability to impart transient alterations in the lung environment in anticipation of future insult could provide an important novel therapy for emerging infectious diseases. In this study, we show that nasal administration of virus-like particles (VLPs) before, or immediately after, lethal challenge with methicillin-resistant Staphylococcus aureus (MRSA) of mice i) ensures complete recovery from lung infection and near absolute clearance of bacteria within 12 hours of challenge, ii) reduces host response-induced lung tissue damage, iii) promotes recruitment and efficient bacterial clearance by neutrophils and $\mathrm{CD}_{11 \mathrm{c}^{+}}$cells, and iv) protects macrophages from MRSA-induced necrosis. VLP-mediated protection against MRSA relied on innate immunity. Complete recovery occurred in VLP-dosed mice with severe combined immunodeficiency, but not in wild-type mice depleted of either $\mathrm{Ly}_{6 \mathrm{G}}{ }^{+}$or CD11c $^{+}$cells. Early IL-13 production associated with VLP-induced $\mathrm{CD} 11 \mathrm{c}^{+}$cells was essential for VLP-induced protection. These results indicate that VLP-induced alteration of the lung environment protects the host from lethal MRSA pneumonia by enhancing phagocyte recruitment and killing and by reducing inflammation-induced tissue damage via IL-13-dependent mechanisms. (Am J Pathol 2012, 181:196-210; http://dx.doi.org/10.1016/j.ajpath.2012.03.018)

The immune system is a plastic entity, in which the history of prior exposures modulates responses to future insults. It is well documented that the occurrence and even the exact sequence of infections can skew the immune response to a subsequent threat toward an inflammatory or anti-inflammatory phenotype, ${ }^{1-5}$ depending on the type of insult, ${ }^{1,5}$ its location, ${ }^{6}$ and even the stage of host development. $^{2}$ The modulatory effect of former insults can be long lasting and can influence the outcome and prognosis of an individual long after the infection has been cleared. $^{2,7}$ For example, acute influenza infection can decrease immune-mediated lung damage associated with subsequent respiratory syncytial virus infection and inhibit replication of vaccinia virus, but it can also enhance replication of lymphocytic choriomeningitis virus and murine cytomegalovirus. ${ }^{7}$ Microbial products, such as $\mathrm{CpG}$, lipopolysaccharide, or other bacterial toxins, can induce protection against a variety of subsequent respiratory pathogens. ${ }^{8-10}$ The homeostatic profile of the lung can also be altered by noninfectious substances. Morphine reduces Toll-like receptor $9-\mathrm{NF}-\kappa \mathrm{B}$ signaling, which leads to impaired clearance of Streptococcus pneumoniae. ${ }^{11}$ Cigarette smoke down-regulates Toll-like receptor 2 expression on alveolar macrophages $(A M s)^{12}$

Supported by grants from the $\mathrm{NIH}[\mathrm{NIH} /$ National Institute of Allergy and Infectious Diseases 1R56Al089458, NIH/IDeA Networks of Biomedical Research Excellence P20 RR16455 (GM123456), NIH/Centers of Biomedical Research Excellence P20 RR020185 (GM123456), and NIH/Rocky Mountain Regional Center for Excellence U54 Al065357], an equipment grant from M.J. Murdock Charitable Trust, and the Montana State University Agricultural Experimental Station.

Accepted for publication March 22, 2012.

Supplemental material for this article can be found at $h$ ttp://ajp. amjpathol.org or at $h$ ttp://dx.doi.org/10.1016/j.ajpath.2012.03.018.

Address reprint requests to Agnieszka Rynda-Apple, Ph.D., or Allen G. Harmsen, Ph.D., Department of Immunology and Infectious Diseases, Montana State University, Bozeman, MT 59717-3610. E-mail: agnieszka. rynda@montana.edu or aharmsen@montana.edu. 
and inhibits expression of proinflammatory cytokines, ${ }^{13}$ which may increase susceptibility to respiratory bacterial infections. Immune imprinting by the nontoxic heat-labile endotoxin (LTK63) of Escherichia coli, delivered as a mucosal adjuvant, induces a transient inflammatory response that reduces inflammation to subsequent type 1 and 2 helper T-cell pathogens (namely, influenza, respiratory syncytial virus, and Cryptococcus neoformans). ${ }^{9}$ Therefore, the ability to transiently modulate the immune environment in preparation for a future infectious challenge, without the need for the induction of harmful inflammation, would be beneficial as preventative and therapeutic treatments.

We have previously reported that pulmonary delivery of a noninfectious, self-assembled protein cage nanoparticle $(\mathrm{PCN})$ induced low-grade inflammation in the absence of tissue damage, yet it enhanced the protection of mice against subsequent sublethal and lethal infections by unrelated viruses, including influenza, severe acute respiratory syndrome virus, and pneumovirus. ${ }^{14}$ This protection is associated with the formation of inducible bronchus-associated lymphoid tissue (BALT) that modulates the local lung environment in the absence of harmful inflammation. ${ }^{14,15}$

PCN is a hollow, spherical protein cage that self-assembles from 24 identical subunits of small heat shock protein, derived from Methanocaldococcus jannaschii. Although PCNs are not of viral origin, their small size (12-nm diameter), self-assembled particulate structure, immunogenicity, and lack of genetic material characterize them as virus-like particles (VLPS). ${ }^{14,16,17}$ Known for their potent adjuvant-like properties, ${ }^{18}$ VLPs can enhance immune responses to parental infectious agents, such as hepatitis $\mathrm{C},{ }^{19}$ dengue virus, ${ }^{20}$ Norwalk virus, ${ }^{21,22}$ or human papillomavirus-induced cervical cancer. ${ }^{23,24}$ In addition, VLPs have been used as a platform for targeting cells ${ }^{16}$ and as a delivery vehicle to present the immune system with fused or conjugated heterologous epitopes, ${ }^{25}$ and even to induce autoantibodies to self molecules involved in chronic diseases. ${ }^{25,26}$ The work reported by our laboratory adds yet another dimension to the VLP-mediated immune modulation (namely, the ability to induce protective immunity to a variety of unrelated antigens). ${ }^{14}$

Invasive methicillin-resistant Staphylococcus aureus (MRSA) infections result annually in more deaths ( $>18,000$ cases) than any other single infectious agent in the United States. ${ }^{27}$ In fact, the mortality associated with MRSA exceeds the mortality resulting from combined, human immunodeficiency, hepatitis, and influenza viruses. ${ }^{28,29}$ The pulsedfield gel electrophoresis type USA300 is the most prevalent community-associated MRSA strain in United States. USA300 typically causes skin and soft tissue infections; however, it is also capable of causing severe staphylococcal diseases, including necrotizing pneumonia that can transpire in otherwise healthy individuals. ${ }^{30,31}$

In the current study, PCN administration before, or shortly after, respiratory infection of mice with MRSA minimized morbidity and prevented mortality. Major reduction of bacterial burden was observed as early as 8 hours after infection in PCN-dosed mice. This protection was associated with improved recruitment of neutrophils and enhanced antibacterial activity of both neutrophils and lung $\mathrm{CD} 11 \mathrm{c}^{+}$cells. The reliance on innate immunity for $\mathrm{PCN}$-mediated protection was indicated by the complete recovery of MRSA-infected mice with severe combined immunodeficiency (SCID) dosed with PCN and the significant loss of protection in PCN-dosed wild-type (WT) mice depleted of either $\mathrm{Ly}_{6 \mathrm{G}}{ }^{+}$neutrophils or $\mathrm{CD} 11 \mathrm{c}^{+}$ cells. Interestingly, PCN-mediated protection was not limited to the lung, because bone marrow (BM) cells from mice intranasally dosed with PCN, but not with PBS, efficiently killed MRSA in vitro. Phenotypical analyses revealed that PCN-dosed mice retained a high M1:M2 macrophage ratio throughout the infection; however, the efficient bacterial killing in $\mathrm{PCN}$-dosed mice was dependent on the early presence of $\mathrm{IL}-13$ and $\mathrm{IL}-4$, in that mice deficient in either of these cytokines had reduced PCNmediated protection against MRSA pneumonia.

\section{Materials and Methods}

\section{Mice}

Male and female WT BALB/C, C57BL/6 (CD45.2), SCID, C-X-C chemokine receptor (CXCR) 2 knockout (KO), $\mathrm{IL}-13 \mathrm{KO}$, and CCR2 $\mathrm{KO}$ mice were bred at Montana State University, Bozeman. The breeding pairs of IL-13 $\mathrm{KO}$ mice were originally generated by Dr. Andrew N.J. McKenzie (Medical Research Council, Laboratory of Molecular Biology, Cambridge, UK) and were kindly provided by Dr. Andrij Holian (University of Montana, Missoula). The breeding pairs of WT and remaining KO mice were obtained from The Jackson Laboratories (Bar Harbor, MI). All mice were maintained at Montana State University Animal Resources Center in individual ventilated cages under high efficiency particulate arresting-filter barrier conditions and were fed sterile food and water ad libitum. All animal care procedures were in accordance with institutional polices for animal health and well-being; 7- to 8-week-old mice were used in all experiments.

\section{Administration of Nanoparticles}

PCNs were prepared as previously described. ${ }^{14,16}$ Mice were lightly anesthetized with oxygen-delivered isoflurane, USP (Piramal, Bethlehem, PA), and were intranasally dosed with $50 \mu \mathrm{L}$ of sterile PBS or PCN containing $100 \mu \mathrm{g}$ of protein. This dosing procedure was repeated five times either daily or every couple of days for 2 weeks, as designated in the figures.

\section{MRSA Infection}

The LAC strain of MRSA (pulsed-field type USA300) was a kind gift from Dr. Jovanka Voyich (Montana State University). The USA300 MRSA was used for infections because it has been described as a causative agent of severe community-onset pneumonia in healthy individuals. ${ }^{32}$ Before MRSA infection, PCN- and PBS-dosed mice were rested for 6 to 7 days to ensure removal of nanoparticles from the body. ${ }^{17}$ Fresh or frozen bacteria grown 
to $\mathrm{OD}_{600} 1.5$ in tryptic soy broth were used for in vivo infections and in vitro cultures. Between $5 \times 10^{7}$ and $5 \times 10^{8}$ (where indicated) microorganisms were used for the infection dose. The erythromycin-sensitive MRSA strain (AH1263 USA300 community-associated MRSA ErmS Lac) ${ }^{33}$ was provided by Dr. Alex Horswill (University of lowa, lowa City).

\section{Collection and Preparation of BALF}

Mice were sacrificed at the designated time points by i.p. administration of a lethal dose of sodium pentobarbital (90 $\mathrm{mg} / \mathrm{kg}$ ), followed by exsanguination when the mice no longer exhibited a pedal reflex. Bronchoalveolar lavage fluid (BALF) was obtained by washing the lungs with $2 \mathrm{~mL}$ of $3 \mathrm{mmol} / \mathrm{L}$ EDTA in PBS in two aliquots of $1 \mathrm{~mL}$ each. The cellular composition of BALF was determined by hemocytometer cell counts and differential counts of cytospins after staining with Quick-Diff solution (Siemens; Medical Solutions Diagnostics, Tarrytown, NY). After centrifugation, the cell-free BALF supernatant was recovered and stored at $-80^{\circ} \mathrm{C}$ for future use to determine levels of cytokines and lung tissue damage.

\section{Histological Analyses}

Lungs used for histological analyses were instilled and fixed in $10 \%$ buffered formalin phosphate (Fisher Scientific, Fairlawn, NJ) for 24 hours. Paraffin-embedded lung sections (5 $\mu \mathrm{m}$ thick) were stained with H\&E and evaluated under a microscope (Eclipse E800; Nikon Inc., Melville, NY) at $\times 10$ and $\times 60$ objective magnification.

\section{Survival and Determination of Bacterial Load}

Mice were monitored bidaily up to 96 hours after infection. Lung bacterial burden was determined based on the counted number of colony-forming units (CFUs) cultured out of $100 \mu \mathrm{L}$ of serially diluted whole lung homogenates (LHs) on tryptic soy agar (TSA) plates at $37^{\circ} \mathrm{C}$ in $5 \% \mathrm{CO}_{2}$. Plated colonies were counted after an overnight incubation.

\section{In Vivo Depletion Studies}

Mice previously dosed with PCN or PBS were i.p. injected with anti-CD11c monoclonal antibody (mAb) [HB224/ N418; for depletion of AMs and dendritic cells (DCs)] or anti-Ly6G mAb (1A8; for depletion of neutrophils), both obtained from BioXcell (West Lebanon, $\mathrm{NH}$ ). The total volume of $500 \mu \mathrm{L}$ (containing $250 \mu \mathrm{g}$ of either $\mathrm{Ab}$ ) was delivered by injection on days $-3,-1$, and 0 in relation to MRSA infection (day 0). Cell depletion was verified by flow cytometry at sacrifice and was determined to be at least $98 \%$ efficient for depletion of $\mathrm{Ly}_{6 \mathrm{G}}{ }^{+}$and $>97 \%$ efficient for depletion of $\mathrm{CD} 11 \mathrm{c}^{+}$cells in both PCN- and PBS-dosed mice.

\section{Neutrophil Preparation, Adoptive Transfer, and Trafficking into the Lungs}

Neutrophils were isolated from the BM of naïve BALB/C mice by Percoll gradient, as previously described. ${ }^{34}$
Briefly, BM was flushed from dissected tibias and femurs, resuspended in HBSS (Mediatech Inc., Herndon, VA), supplemented with $0.1 \%$ bovine serum albumin and $1 \%$ glucose, and filtered through a 70- $\mu \mathrm{m}$ nylon cell strainer (BD, Franklin Lakes, $\mathrm{NJ}$ ) to remove clumps and bone particles. BM cells were centrifuged $(600 \times g, 10 \mathrm{~min}-$ utes) and resuspended in 45\% Percoll PLUS solution (GE Healthcare Bio-Sciences Corp, Piscataway, NJ). The Percoll gradient was prepared by layering the polypropylene tube with $81 \%, 62 \%, 55 \%$, and $50 \%$ of Percoll solution in HBSS. The BM cells in $45 \%$ Percoll were carefully suspended on a top of the gradient. After centrifugation $(1600 \times g$, 30 minutes), the neutrophil fraction (band between $81 \%$ and $62 \%$ Percoll gradient) was carefully removed and washed twice with HBSS. The purity of the neutrophil fraction was confirmed by microscopic examination of cells after the Diff-Quick staining procedure and was assessed to be $>97 \%$ pure. Purified neutrophils were labeled with Vybrant-Dil (Molecular Probes, Eugene, OR) dye, according to the manufacturer's recommendations. Mice were dosed nasally with PCN or PBS for 5 consecutive days. One week after the last dose, mice were infected with MRSA and, 1 hour later, adoptively transferred through tail vein injection with $1 \times 10^{7}$ Vybrant-labeled neutrophils. At 4 hours after adoptive transfer, mice were sacrificed. The number of $\mathrm{Vybrant}^{+}$ cells in BALF was determined by fluorescence-activated cell sorting (FACS).

\section{Cytokine Analyses}

Cytokine analyses were performed on cell-free BALF. Levels of interferon- $\gamma$, tumor necrosis factor (TNF)- $\alpha$, IL-6, and monocyte chemoattractant protein (MCP)-1 were determined by Cytometric Bead Array (BD Bioscience, San Jose, CA), according to manufacturer's recommendations, and analyzed by BD LSRII Flow Cytometer (BD Bioscience) using BD Cytometric Bead Array analysis software. Levels of IL-13 and IL-4 were determined by a sandwich enzyme-linked immunosorbent assay kit (ReadySET-Go; eBioscience, San Diego, CA). BALF samples were tested in triplicate.

\section{Flow Cytometry}

A single-cell suspension was obtained by centrifugation of BALF. Red blood cells were lysed with AKC Lysis Buffer $\left(150 \mathrm{mmol} / \mathrm{L} \mathrm{NH} \mathrm{NCl}_{4}, 1 \mathrm{mmol} / \mathrm{L} \mathrm{KHCO}_{3}\right.$, and 0.1 $\mathrm{mmol} / \mathrm{L} \mathrm{Na} \mathrm{EDTT}_{2}$; $\mathrm{pH} 7.2$ to 7.4 ) in room temperature for 5 minutes. Cells were washed with PBS twice and blocked with $\mathrm{Fc}$ receptor block $\left(2.4 \mathrm{G}_{2}\right.$ hybridoma made in house) for 20 minutes at room temperature. Cells were stained with fluorochrome-labeled antibodies to extracellular markers: CD11c (clone N418; eBioscience), CD11b (clone M1/70; eBioscience), F4/80 (clone BM8; eBioscience), major histocompatibility complex (MHC) II (clone M5/114.15.2; eBioscience), and CD206 (clone MR5D3; AbD Serotec, Raleigh, NC). After a 30-minutes incubation, cells were washed twice in FACS buffer ( $1 \%$ fetal bovine serum/PBS) and stained with streptavidin-allophycocyanin for 30 minutes. After staining for extracellu- 
lar markers, cells were washed in FACS buffer and fixed in $4 \%$ paraformaldehyde for 20 minutes. Fixed cells were washed once in FACS buffer and in $0.2 \%$ saponin made in FACS buffer, and they were stained for 30 minutes with phosphatidylethanolamine-conjugated Abs to mouse IL-13 (clone eBio13A; eBioscience) or with rat lgG1 isotype control Ab (clone eBRG1; eBioscience). Samples were acquired on FACSCanto running FACSDiva software (both obtained from BD Bioscience). Approximately 50,000 events were routinely acquired per sample. FlowJo software (Tree Star, Inc., Ashland, OR) was used for analysis.

\section{Cell Selection, Bacterial Killing, and Bacterial Uptake Assays}

A single-cell suspension obtained after red blood cell lysis and filtration (30 $\mu \mathrm{m})$ of $\mathrm{LH}$ was run through magnetic-activated cell sorting (MACS)-positive selection columns to obtain pure $\mathrm{Ly}_{6 \mathrm{G}}{ }^{+}$and $\mathrm{Ly}_{6} \mathrm{G}^{-}$cell populations ( $>97 \%$ and $>98 \%$ purity, respectively). In separate experiments, LH cells were first selected for CD11c ${ }^{+}$ cells (positive MACS CD11c selection) and the CD11 ${ }^{-}$ cells were subsequently depleted of $\mathrm{Ly} 6 \mathrm{G}^{+}$cells by MACS Ly6G depletion columns (>97\% purity). The purity of all fractions was confirmed by FACS, according to manufacturers' recommendations.

\section{Bacterial Killing Assay}

For these experiments, designated populations of cells were plated in a $1: 1$ ratio with normal mouse serum (NMS)-opsonized MRSA (50\% NMS, 30 minutes, $37^{\circ} \mathrm{C}$, $\left.5 \% \mathrm{CO}_{2}\right)$ on NMS-coated flat-well culture plates $(100 \%$ NMS, 30 minutes, $37^{\circ} \mathrm{C}, 5 \% \mathrm{CO}_{2}$ ). The killing assay was conducted at $37^{\circ} \mathrm{C}$ for 1.5 and 3 hours. After this time, $0.1 \%$ saponin was added to each well to release internalized bacteria and total CFUs were determined for each experimental sample by plating the 10 -fold dilutions on TSA plates. In the experiments in which two different variants of the LAC strain were used (in vivo, MT1263 erythromycin-sensitive LAC; and in vitro, WT LAC erythromycin resistant), the bacterial burden was evaluated by plating on TSA/erythromycin plates $(25 \mu \mathrm{g} / \mathrm{mL})$.

\section{Bacterial Uptake Assay}

This assay was performed as previously described. ${ }^{35}$ Briefly, cells isolated from BMs of mice dosed with PCN and PBS ( $>78 \%$ polymorphonuclear cells, as determined by differential count) were plated on tissue culture plates previously incubated at $37^{\circ} \mathrm{C}$ for 30 minutes with $100 \%$ NMS or heat-inactivated NMS or incubated without serum. Cells were left to adhere to the wells for 15 minutes at room temperature, followed by a 10-minute incubation on ice to prevent activation. NMS-opsonized, heat-inactivated NMS-opsonized, or not opsonized MRSA was added in a 1:1 ratio to the wells, and plates were synchronized by centrifugation at $8^{\circ} \mathrm{C}, 500 \times g$ for 7 minutes. $^{35}$ After synchronization, cells were incubated at $37^{\circ} \mathrm{C}$ for 30 minutes. The uptake of bacteria was stopped after 30 minutes, and $40 \mu \mathrm{g} / \mathrm{mL}$ of gentamicin was added to each well to kill the extracellular bacteria. Subsequently, total supernatants were removed by aspiration and cells were resuspended in $0.1 \%$ saponin solution to allow the release of intracellular bacteria. Wells containing MRSA only (but no mammalian cells) were used as a baseline for gentamicin killing of extracellular bacteria.

\section{Statistical Analyses}

The differences between treatment groups were analyzed using the Student's $t$-test or analysis of variance. For the differences in survival, Kaplan-Meier curves were plotted and analyzed using GraphPad Prism software, version 4.0 (GraphPad, La Jolla, CA). Statistical differences of $P<0.05$ were considered significant.

\section{Results}

\section{Nasal Administration of PCNs Protects from Pulmonary MRSA Infection}

Our previous studies ${ }^{14}$ indicated that nasal administration of a type of VLP, PCN, prevented body weight loss and significantly reduced lung viral titers in mice infected with murine-adapted influenza or severe acute respiratory syndrome viruses. Herein, we determined whether nasal administration of PCN prevented mortality associated with pulmonary MRSA infection. WT mice dosed five times with PCN and rested for a week before MRSA infection, compared with PBS-dosed mice, showed more than a millionfold reduction in bacterial titers in the lungs (Figure 1A). At 72 hours after infection with $5 \times 10^{7} \mathrm{CFUs}$ of MRSA per dose, we isolated $1.9 \times 10^{3} \mathrm{CFUs}$ of bacteria from the lungs of PCN-dosed mice and $1.2 \times 10^{9}$ CFUs of bacteria from the lungs of PBS-dosed mice. Significant decreases in bacterial burden in spleen, liver, and kidney were observed in PCN-dosed mice when compared with PBS-dosed mice (see Supplemental Figure S1 at $h$ ttp://ajp.amjpathol.org). Interestingly, the blood of both PCN- and PBS-dosed mice was virtually free of bacteria up to 72 hours after infection and over the range of challenge doses used in multiple experiments $\left(5 \times 10^{7}\right.$ to $5 \times 10^{8} \mathrm{CFUs}$; data not shown). The reduction of lung bacterial burden directly correlated to survival of all PCNdosed mice (Figure 1B). In contrast to PCN-dosed mice, the mortality of PBS-dosed mice reached $>50 \%$ at 24 hours after infection, which was directly associated with high bacterial burden in lungs. The mortality rate of PBS-dosed mice was dependent on the infectious dose and varied between approximately $50 \%$ survival at 72 hours for PBS-dosed BALB/c mice infected with $5 \times 10^{7} \mathrm{CFU}$ s and $<20 \%$ survival for these mice when infected with $5 \times 10^{8} \mathrm{CFUs}$ of MRSA. In contrast to PBS-dosed mice, PCN-dosed BALB/C mice were entirely protected from MRSA-related mortality in all dose regimens tested ( $5 \times 10^{7}$ to $\left.5 \times 10^{8} \mathrm{CFUs}\right)$. 

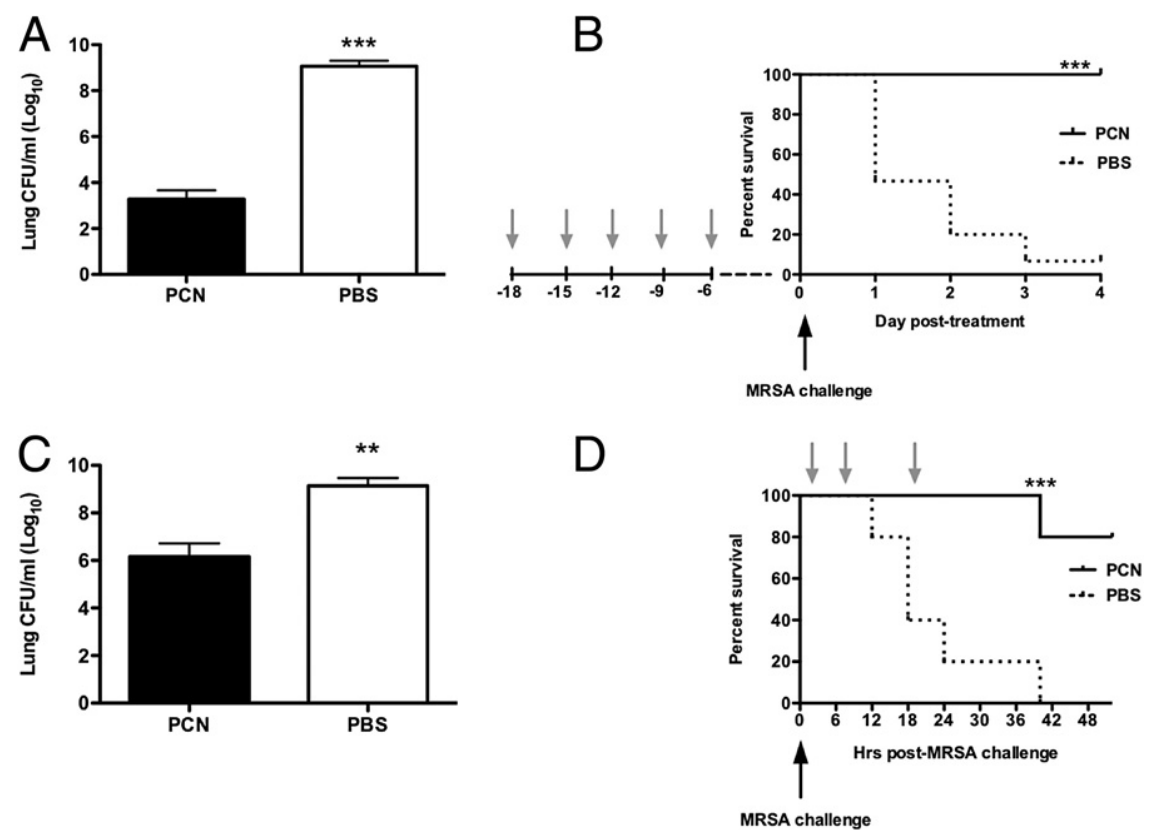

Figure 1. Administration of VLPs protects against MRSA pneumonia. A and B: Female $\mathrm{BALB} / \mathrm{c}$ mice are nasally dosed five times every other day over 2 weeks (arrow) with PCN or PBS. One week after the last dose, mice are challenged with MRSA. C and D: Mice are infected with MRSA and then treated with PCN or PBS three times: 1,7 , and 19 hours after infection. $\mathbf{A}$ and $\mathbf{C}$ : The bacterial burden in lungs is determined 72 hours after infection. B and $\mathbf{D}$ : The survival of mice is monitored daily. Each experiment is repeated three times. The mean \pm SD from 9 to 15 mice per group (representing three combined independent experiments) is shown. ${ }^{* * *} P<0.01,{ }^{* * * *} P<0.001$ versus $\mathrm{PCN}-$ dosed mice.

\section{Nasal Delivery of P22 VLP Reduces Bacterial Burden in Lungs of MRSA-Infected Mice}

To determine whether induced protection against MRSA pneumonia was specific to PCN, we investigated whether P22 VLP was also protective. The P22 VLP was derived from the P22 bacteriophage that infected Salmonella. ${ }^{36,37}$ This VLP consisted of 420 identical copies of the P22 coat protein (each $45.5 \mathrm{kDa}$ ); it did not contain nucleic acids and, thus, was not infectious. Nasal administration of P22 VLP before MRSA infection prevented mortality and reduced bacterial burdens in the lungs, similar to PCN administration (see Supplemental Figure S2 at http://ajp.amjpathol.org).

\section{PCN Administration Shortly after MRSA Challenge Resolves Pneumonia and Protects from Mortality}

Next, we investigated whether PCN, given after exposure to MRSA infection, also protected mice from lethal MRSA pneumonia. Indeed, intranasal therapy with PCN started 1 hour after MRSA challenge, and repeated again at 7 and 19 hours after infection, significantly reduced bacterial burden (>1000-fold reduction) and prevented mortality (Figure 1, C and D).

\section{The Early Events of the First 12 Hours after MRSA Infection Are Crucial for Disease Resolution in PCN-Dosed Mice}

To determine how soon after MRSA infection PCN administration began to exert its protective effects, PCN-dosed mice were sacrificed at designated time points after MRSA (Figure 2). By 12 hours after infection, a 10-fold difference in bacterial burden was present between PCNand PBS-dosed mice; by 72 hours, the lungs of PCN- dosed mice showed more than a millionfold reduction in bacterial burden when compared with PBS-dosed mice (Figure 2A). This decline of bacterial numbers in PCNdosed mice was coupled with increased numbers of neutrophils and macrophages in the first 12 hours after MRSA infection (Figure 2, B and C). Neutrophils were absent in the lung lavages of PCN- and PBS-dosed mice at infection (0 hours). Significantly more macrophages were present in the BALF of PCN-dosed mice than in the PBS-dosed mice at infection. At 3 hours after infection, the numbers of macrophages in $\mathrm{PCN}$-dosed mice remained significantly higher when compared with PBSdosed mice, but were notably reduced when compared with uninfected PCN-dosed mice. This decline was most likely a result of migration of macrophages to the lung parenchyma or more firm adherence to alveolar epithelium, a phenomenon described originally by Sonozaki and $\mathrm{Cohen}^{38}$ as a macrophage disappearance reaction. In PCN-dosed mice, neutrophils and macrophages remained elevated between 3 and 12 hours after infection, but were reduced by 24 hours (Figure 2, B and C). After 24 hours, and in compliance with the return of homeostatic conditions in the lungs of PCN-dosed mice, neutrophil numbers were reduced to trace levels, whereas AMs repopulated the lung. In contrast to PCN-dosed mice, the numbers of neutrophils in PBS-dosed mice increased steadily until after 48 hours of infection. The numbers of macrophages in PBS-dosed mice did not start to increase until 48 hours after infection (Figure 2C). Bacterial burden in the lungs of PBS-dosed mice reflected the delayed and/or inefficient macrophage and neutrophil responses and remained high throughout the experiment (Figure 2A).

Successful clearance of MRSA required an inflammatory response, but an excess of inflammation is responsible for tissue damage and decreased survival of MRSAinfected mice. ${ }^{39,40}$ In this regard, the levels of lactate 

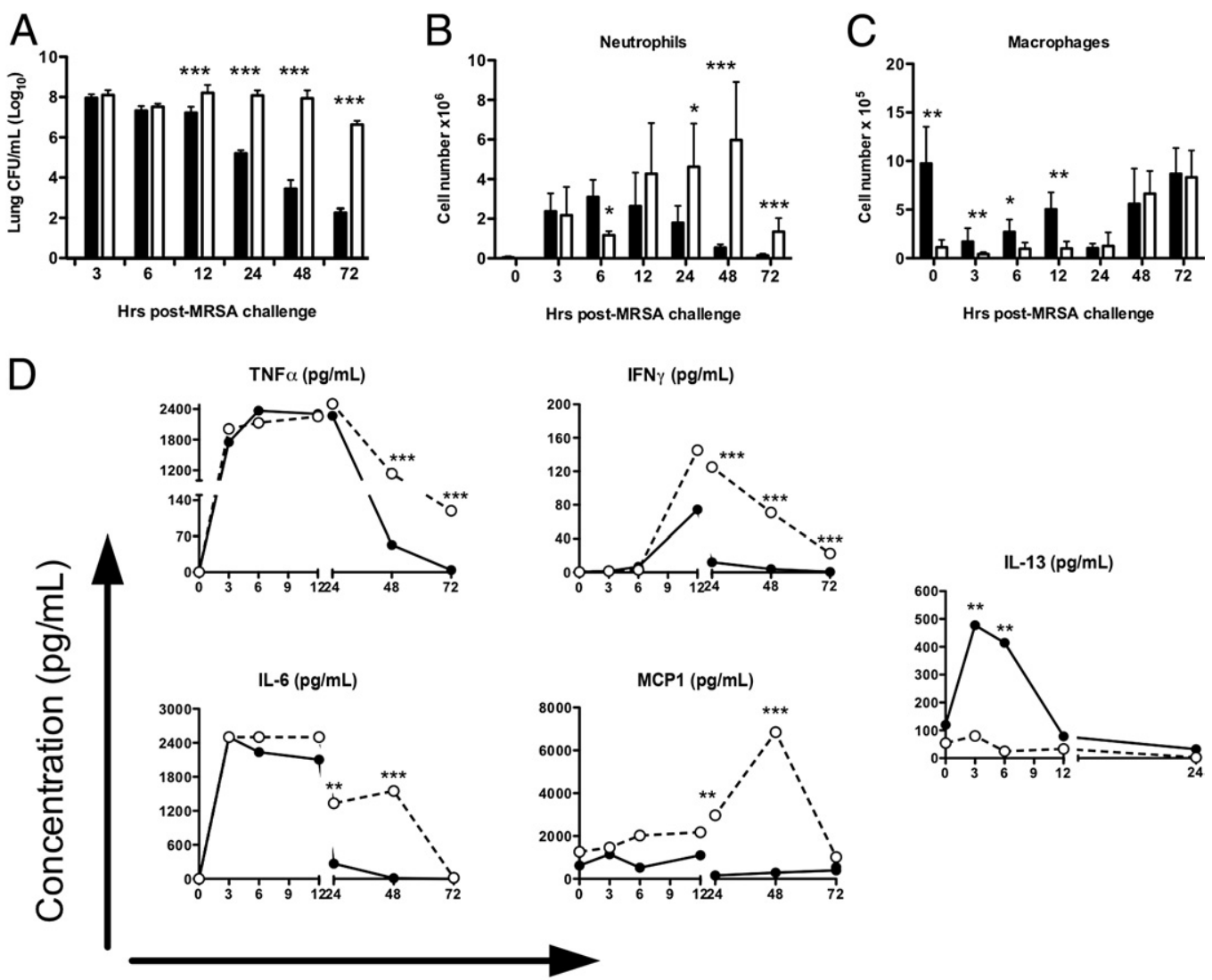

Hrs post-MRSA challenge

Figure 2. PCN reduces bacterial burden and down-regulates harmful inflammation in the first 24 hours after infection. Mice are dosed five times daily with PCN or PBS a week before MRSA infection, and were sacrificed at the designated time points. A: The LHs are evaluated for bacterial growth. B-D: BALF is collected on sacrifice. Numbers of neutrophils $(\mathbf{B})$ and mononuclear cells $(\mathbf{C})$ are enumerated by differential count. D: Cell-free supernatant is evaluated for production of cytokines TNF- $\alpha$, interferon (IFN)- $\gamma$, IL-13, IL-6, and MCP-1. Experiments are repeated three times. The mean \pm SD of five to six mice per group is shown. ${ }^{*} P<$ $0.05,{ }^{* *} P<0.01$, and ${ }^{* * * *} P<0.001$ versus PCN-dosed mice. Black bars/dots, PCN; white bars/dots, PBS.

dehydrogenase (LDH) and albumin in BALF of MRSAinfected PCN-dosed mice remained low throughout the disease, whereas in PBS-dosed mice, these levels were increasing until 48 hours after infection (see Supplemental Figure S3, A and B, at http://ajp.amjpathol.org). In addition, starting at 6 hours after MRSA infection, levels of albumin in BALF of PBS-dosed mice were significantly increased when compared with PCN-dosed mice. This was important because, at 6 hours after infection, no differences in lung bacterial burden were seen between PCN- and PBS-dosed mice. Therefore, the lack of increases in albumin in PCN-dosed mice was indicative of reduced host response-mediated tissue damage in $\mathrm{PCN}$ dosed mice. There were no statistical differences in BALF levels of TNF- $\alpha$, interferon- $\gamma, \mathrm{IL}-6$, and MCP- 1 in the first 6 hours after MRSA infection between PCN- and PBSdosed mice (Figure 2D). Between 12 and 24 hours after MRSA infection, when the bacterial burdens in PCNdosed mice were significantly less, the levels of these inflammatory cytokines started to decline. However, in PBS-dosed mice, these cytokines remained high (IL-6 and $\mathrm{TNF}-\alpha$ ) or continued to increase (MCP-1), which was associated with the lack of infection resolution and consistently high bacterial burden in the lungs of these mice (Figure 2). Interestingly, of the anti-inflammatory cyto- kines tested, only levels of IL-13 were significantly elevated in the BALF of PCN-dosed mice, up to 8 hours after infection (Figure 2D).

\section{PCN Reduces Lung Tissue Pathology}

In concurrence with decreased levels of LDH and albumin and more efficient clearance of bacteria by innate cells in PCN-dosed mice, we observed that at 20 hours after MRSA infection, PCN-dosed mice showed greatly reduced signs of tissue damage, as evaluated by staining of lung sections with H\&E (Figure 3). In agreement with our previous report, ${ }^{14}$ iBALT was present in PCN-but not in PBS-dosed mice, in association with airways and blood vessels (Figure 3). Phagocytic cells in the lung parenchyma of PCN-dosed mice were intact; at 20 hours after MRSA infection, these cells consisted predominantly of mononuclear cells that presumably were returning to the lung to re-establish tissue homeostasis (Figure 3). In contrast to PCN-dosed mice, phagocytes in the lungs of PBS-dosed mice were often disrupted and filled with bacteria (Figure 3). The vasculature of these mice was greatly congested and showed signs of interstitial edema (Figure 3). 

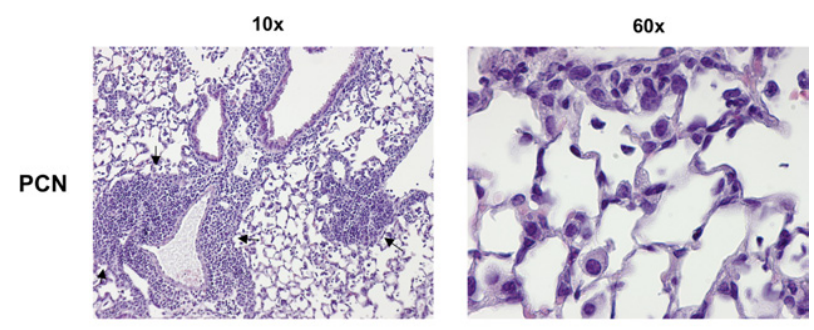

PBS
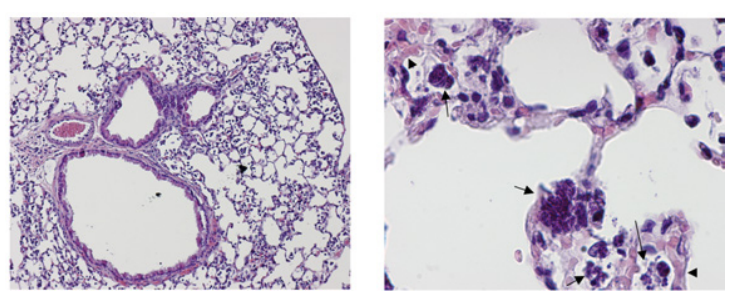

Figure 3. PCN protects mice from MRSA-induced lung tissue pathology. $\mathrm{C} 57 \mathrm{BL} / 6$ mice are nasally dosed with $\mathrm{PCN}$ or PBS five times daily and challenged with $1 \times 10^{8}$ CFUs of MRSA a week later. At 20 hours after MRSA infection, mice are sacrificed and their lungs are fixed in formalin. Embedded sections are then stained with H\&E and analyzed by microscopy. Pictures of representative lung sections from $\mathrm{PCN}$ - and $\mathrm{PBS}$-dosed mice, taken using $\times 10$ and $\times 60$ magnification objectives, are shown. Arrows, iBALT $(\times 10$ PCN picture) and phagocytes filled with bacteria or disrupted phagocytes $(\times 60$ PBS picture). Arrowheads, interstitial congestion and edema $(\times 60$ PBS picture).

\section{PCN-Mediated Protection Against MRSA Subsides between 3 and 5 Weeks after \\ Treatment}

To determine how long PCN-mediated protection persisted, PCN- or PBS-dosed mice were infected with $5 \times$ $10^{7}$ CFUs of MRSA at $1,2,3$, or 5 weeks after PCN or PBS treatment. Mice infected with MRSA either 1 or 2 weeks after PCN treatment showed significantly improved bacterial clearance $\left(<4 \log _{10}\right)$ when compared with PCNdosed mice rested for either 3 or 5 weeks before challenge (>5 $\log _{10}$; see Supplemental Figure S4 at $h t t p: / /$ ajp.amjpathol.org). No difference in bacterial burden was observed between PCN-dosed mice that were infected with MRSA at either 3 or 5 weeks after treatment, but PCN-dosed mice at all time points showed improved bacterial clearance when compared with their respective PBS-dosed MRSA-infected control mice.

\section{Different Phenotypes of $\mathrm{CD} 11 \mathrm{C}^{+}$Macrophages and DCs Are Induced in Response to MRSA Infection in the Lungs of PCN-Dosed Mice}

Our results, presented in Figure 2, suggested a role for macrophages in PCN-mediated protection from MRSA. In an effort to define the phenotype and kinetics of macrophages, which in a steady-state lung expressed CD11C, ${ }^{41}$ FACS analyses were performed on cells isolated from BALF (Figure 4) and LHs (data not shown) of mice infected with $5 \times 10^{7}$ CFUs of MRSA. By gating on the total live cells (confirmed by staining with 7-aminoactinomycin D), we confirmed that at time 0 hours (before MRSA infection), approximately $90 \%$ of the cells recovered in the BALF of both PCN- and PBS-dosed mice were $\mathrm{CD}_{11 \mathrm{C}^{+}}$(Figure 4A and Table 1). More important, even though $>90 \%$ of cells in the BALF of PBS-dosed mice were $\mathrm{CD} 11 \mathrm{C}^{+}$, the absolute number of these cells represented just a fraction of $\mathrm{CD}_{11 \mathrm{c}^{+}}$cells in the BALF of PCN-dosed mice (Table 1). Early after MRSA infection, the percentage of cells expressing CD11c significantly decreased in the BALF of PBS-dosed mice to approximately $40 \%$ at 3 hours after infection and to $<10 \%$ at 24 hours after infection (Figure 4A). In contrast to PBSdosed mice, in the BALF of PCN-dosed mice, CD11C ${ }^{+}$ cells remained at approximately $70 \%$ throughout the infection. CD $11 b^{+}$cells that were virtually absent in PCNand PBS-dosed mice before infection (Figure 4A: at 0 hours, $<6 \%$ of $\mathrm{CD} 11 \mathrm{~b}^{+}$cells) increased significantly after infection in PBS-dosed mice (approximately $50 \%$ at 3
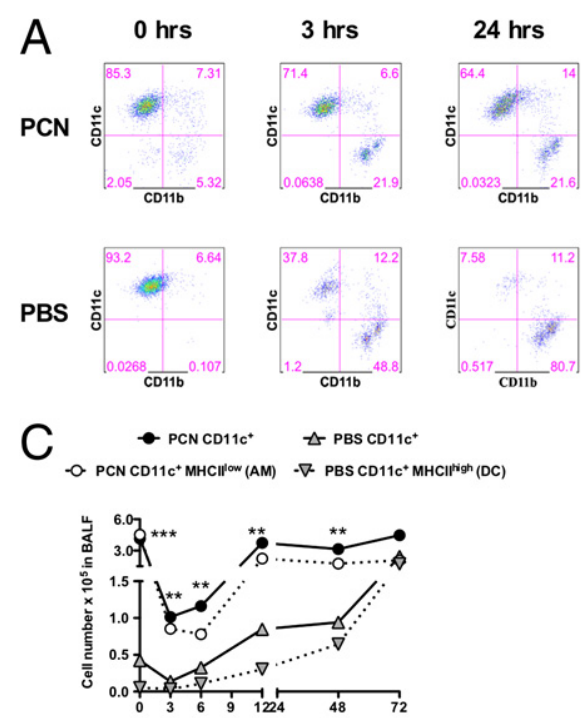

Hrs post-MRSA challenge

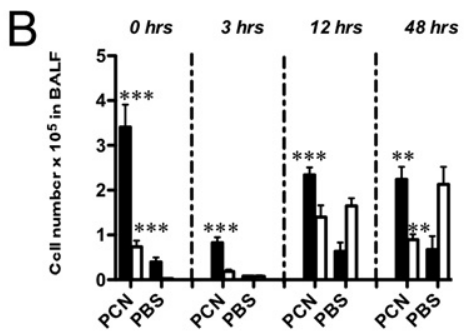

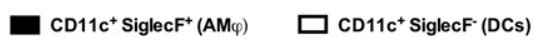

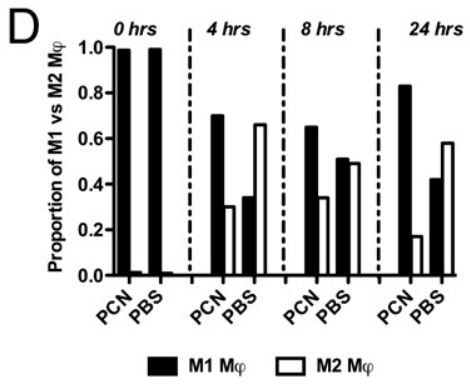

Figure 4. $\mathrm{CD}_{11 \mathrm{c}^{+}}$macrophages and DCs are induced by PCN administration. Mice are dosed five times daily with PCN or PBS a week before MRSA infection. Mice are sacrificed at designated time points after infection, and cells isolated from BALF are stained and analyzed by FACS The gating strategy is as follows. A: The live cells gate is set on FCS (forward scatter; representing cell volume) versus SSC (side scatter; representing the inner complexity of the particle like granularity of a cell). Staining for CD11c versus $\mathrm{CD} 11 \mathrm{~b}$ is determined by gating total live cells. Representative FACS plots are shown. B: The expression of SiglecF is evaluated on live

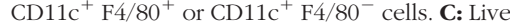
cells are gated for $\mathrm{F}_{4} / 80^{+}$cells and then for $\mathrm{CD}_{11 \mathrm{c}^{+}}$versus $\mathrm{MHCII}^{+}$cells. CD $11 \mathrm{c}^{+} \mathrm{MHCII}^{\mathrm{low}}$ AMs are shown for PCN-dosed mice, and $\mathrm{CD}_{11 \mathrm{c}^{+} \mathrm{MHCI}}{ }^{\text {high }}$ DCs are shown for PBSdosed mice. D: In an independent experiment, the presence of $\mathrm{M} 1\left(\mathrm{CD} 11 \mathrm{c}^{+} \mathrm{CD} 206^{-}\right)$and $\mathrm{M} 2$ $\left(\mathrm{CD} 11 \mathrm{c}^{+} \mathrm{CD} 206^{+}\right)$cells is determined after gating on live $\mathrm{F} 4 / 80^{+}$cells. Each panel represents the results from a single experiment (mean \pm SD from five mice per group). Each experiment is repeated two to three times. ${ }^{* * *} P<0.01$, ${ }^{* * * *} P<$ 0.001 versus PBS-dosed mice. 
Table 1. Kinetics of $\mathrm{CD} 11 \mathrm{c}^{+}$Cells in the BALF of PCN- and PBS-Dosed Mice

\begin{tabular}{|c|c|c|c|c|c|c|c|}
\hline $\begin{array}{l}\text { Time after } \\
\text { MRSA } \\
\text { (hours) }^{\star}\end{array}$ & Treatment $^{\dagger}$ & $\begin{array}{c}\% \text { of Total } \\
\text { F4/80 } \\
\text { cells }{ }^{\ddagger}\end{array}$ & $\begin{array}{c}\text { No. of total } \\
\text { F4/80 }{ }^{+} \mathrm{CD} 11 \mathrm{C}^{+} \\
\text {cells }^{\S}\end{array}$ & $\begin{array}{c}\text { No. of } \\
\text { (SiglecF }^{+} \mathrm{CD} 11 \mathrm{c}^{+} \\
\text {cells) } \mathrm{AMs}^{\text {I }}\end{array}$ & $\begin{array}{l}\% \text { of }(\text { SiglecF } \\
\left.\text { CD11 }^{+}\right) \mathrm{AMs}^{+}\end{array}$ & $\begin{array}{l}\% \text { of }(\text { SiglecF } \\
\text { CD11 } \\
+\end{array}$ & $\begin{array}{l}\text { No. of (SiglecF- } \\
\text { CD11 } \mathrm{c}^{+} \text {) DCs }\end{array}$ \\
\hline 0 & PCN & $85.6+3.4$ & $4.2 \times 10^{5 \|}$ & $3.4 \times 10^{5 \|}$ & $80.9+4.7$ & $19.1+4.7^{* \star}$ & $0.7 \times 10^{5 * \star}$ \\
\hline 0 & PBS & $91.0+2.4$ & $0.4 \times 10^{5}$ & $0.4 \times 10^{5}$ & $94.2+1.6$ & $5.8+1.6$ & $0.03 \times 10^{5}$ \\
\hline 3 & PCN & $42.66+15.2^{\dagger+}$ & $1 \times 10^{5 * *}$ & $0.8 \times 10^{5 * *}$ & $81+1.8^{\|}$ & $19+1.8^{11}$ & $0.2 \times 10^{5 \|}$ \\
\hline 3 & PBS & $21.5+4.2$ & $0.14 \times 10^{5}$ & $0 . \times 10^{5}$ & $50.4+6.9$ & $49.6+13.9$ & $0.08 \times 10^{5}$ \\
\hline 6 & PCN & $15.6+5.9$ & $1.2 \times 10^{5 \|}$ & $0.9 \times 10^{5 \|}$ & $78.1+7.0$ & $11.9+3.7^{\dagger \dagger}$ & $0.2 \times 10^{5 \|}$ \\
\hline 6 & PBS & $11.34+3.6$ & $0.33 \times 10^{5}$ & $0.3 \times 10^{5}$ & $88.1+3.7^{+\dagger}$ & $21.9+7.0$ & $0.04 \times 10^{5}$ \\
\hline 12 & PCN & $18.3+2.2^{* *}$ & $3.8 \times 10^{5 \|}$ & $2.34 \times 10^{5 \|}$ & $63.86+10.7^{\|}$ & $36.1+13^{1+}$ & $1.4 \times 10^{5}$ \\
\hline 12 & PBS & $3.74+1.22$ & $0.8 \times 10^{5}$ & $0.6 \times 10^{5}$ & $35.32+7.5$ & $64.68+14.6$ & $1.6 \times 10^{5}$ \\
\hline 24 & PCN & $30+11^{* *}$ & $0.9 \times 10^{5+t}$ & $0.8 \times 10^{5+t}$ & $72.58+4.9 \|$ & $27.4+4.9^{\|}$ & $0.3 \times 10^{5}$ \\
\hline 24 & PBS & $4.32+1.1$ & $0.24 \times 10^{5}$ & $0.3 \times 10^{5}$ & $49.32+6.7$ & $50.68+11.7$ & $0.3 \times 10^{5}$ \\
\hline 48 & PCN & $41.6+9.4^{* *}$ & $3.2 \times 10^{5 \|}$ & $2.2 \times 10^{5+t}$ & $69.1+5.1^{\star \star}$ & $30.9+5.1^{\star \star}$ & $1.0 \times 10^{5+t}$ \\
\hline 48 & PBS & $6.8+2.9$ & $0.9 \times 10^{5}$ & $0.7 \times 10^{5}$ & $29.09+6.9$ & $70.91+12.0$ & $2.1 \times 10^{5}$ \\
\hline 72 & PCN & $47.9+8.9^{\star \star}$ & $4.5 \times 10^{5+t}$ & $2.5 \times 10^{5 \|}$ & $71.72+7.2^{\star \star}$ & $28.28+7.3^{\star \star}$ & $1.0 \times 10^{5+t}$ \\
\hline 72 & PBS & $15.2+3.9$ & $2.4 \times 10^{5}$ & $1.0 \times 10^{5}$ & $34.4+8.3$ & $65.6+8.3$ & $1.5 \times 10^{5}$ \\
\hline
\end{tabular}

${ }^{*} \mathrm{~A}$ week after the last PCN or PBS treatment, mice were infected with MRSA.

${ }^{\dagger} \mathrm{BALB} / \mathrm{c}$ mice were intranasally dosed with PCN or PBS and rested for a week.

‡BALF cells were stained and analyzed by FACS. The gating strategy was as described in the legend to Figure 4.

$\S$ The absolute numbers of cells were calculated by multiplying the percentage of live cells by the cell number counted under hemocytometer/100\%.

"SiglecF ${ }^{+}$and SiglecF $^{-}$were determined by gating on $\mathrm{CD}_{11 \mathrm{c}^{+}}$cells.

$\| P<0.01$ versus PBS-dosed mice.

${ }^{\star \star} P<0.001$ versus PBS-dosed mice.

${ }^{+\dagger} P<0.05$ versus PBS-dosed mice.

hours and approximately $80 \%$ at 24 hours), but in the BALF of PCN-dosed mice, these cells peaked at approximately $20 \%$ at 3 hours after infection and these percentages remained unchanged until 24 hours after infection (Figure 4A). Despite their lower percentage, the numbers of $\mathrm{CD}_{11 \mathrm{~b}^{+}}$cells were similar between PCN- and PBSdosed mice (data not shown).

In the lungs, cells that expressed CD11c could be AMs and/or DCs. ${ }^{42}$ We used multiple staining strategies to distinguish between AMs and DCs, including either differential expression of SiglecF ${ }^{43-45}$ and $\mathrm{F} 4 / 80^{42}$ (Figure $4 \mathrm{~B}$ ) or various expression levels of $\mathrm{MHCII}^{46}$ (Figure 4C). We confirmed that $\mathrm{CD}_{11 \mathrm{C}^{+} \mathrm{MHCll}} \mathrm{I}^{\text {low }}$ cells were also SiglecF $^{+}$(and, thus, were AMs) and $\mathrm{CD}_{11 \mathrm{c}^{+} \mathrm{MHCl}}{ }^{\text {high }}$ cells were SiglecF ${ }^{-}$(and, thus, were DCs; data not shown). When compared with PBS-dosed mice, the num-

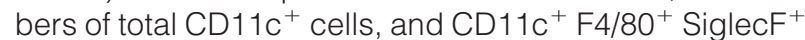
$\mathrm{AM}$ and SiglecF- DCs, were significantly higher in PCNdosed mice before and shortly after MRSA infection (Figure 4, A and B, and Table 1). Even though numbers of AMs $\left(\mathrm{CD}_{11 \mathrm{C}^{+}}\right.$SiglecF$^{+}$cells in Figure $\left.4 \mathrm{~B}\right)$ remained significantly lower in PBS-dosed mice until 48 and 72 hours after infection, the numbers of DCs $\left(\mathrm{CD}_{11 \mathrm{c}^{+}}\right.$SiglecF $^{-}$ cells in Figure $4 \mathrm{~B}$ and $\mathrm{CD} 11 \mathrm{C}^{+} \mathrm{MHCl}{ }^{\text {high }}$ cells in Figure $4 C$ ) in these mice increased rapidly at 12 hours after infection and significantly exceeded the numbers of DCs in PCN-dosed mice at later points after infection (Figure 4B and Table 1). M1 macrophages are considered to be the short-term responders to infections, whereas the M2 phenotype is usually associated with wound healing and less damaging chronic inflammatory responses. ${ }^{47,48}$ We observed that, in PCN-dosed mice at 4 hours after MRSA infection, there was threefold more $\mathrm{M} 1\left(\mathrm{CD} 11 \mathrm{c}^{+} \mathrm{CD}_{206}{ }^{-}\right)$ than $\mathrm{M} 2\left(\mathrm{CD} 11 \mathrm{C}^{+} \mathrm{CD}_{206^{+}}\right.$) macrophages (Figure 4D). At 8 hours after infection in PCN-dosed mice, the dominance of M1 phenotype was smaller, yet still significant (twofold more of M1 macrophages); at 24 hours after infection, when the bacterial burden in the lungs of $\mathrm{PCN}$-dosed mice was further diminishing (Figure 2A), the M1 prevalence over the M2 phenotype was fivefold. Contrary to PCN-dosed mice, PBSdosed mice had almost threefold as many M2 macrophages as M1 at 4 hours after infection. At 8 hours after infection in these mice, the numbers of M1 and M2 macrophages in BALF were similar, but at 24 hours after infection, the numbers of $\mathrm{M} 2$ cells again exceeded the numbers of M1 cells (Figure 4D).

\section{CD11C ${ }^{+}$Cells and Neutrophils from PCN- Dosed Mice Are More Efficient in Killing MRSA}

Our results thus far suggested a role for macrophages and neutrophils in PCN-induced protection. Thus, we determined whether these cells in PCN-dosed mice were better in killing MRSA than cells from PBS-dosed mice. Morphological assessment of these cells at 3 hours after MRSA infection indicated that mononuclear cells in the BALF of PCN-dosed mice were, for the most part, intact and appeared to contain bacteria (Figure 5A). At the same time, plasma membranes of mononuclear cells in the BALF of PBS-dosed mice were largely disrupted and, consequently, cell-free portions of the BALF from these mice contained frequent bacteria (Figure $5 \mathrm{~A}$ ). At 3 hours after infection, in contrast to mononuclear cells in the BALF of PCN-dosed mice, the morphological appearance of mononuclear cells in the BALF of PBS-dosed mice suggested that these cells underwent necrosis.

Results described in Figure 4D showed that, in contrast to macrophages in PBS-dosed mice, these cells in PCN-dosed mice were predominantly M1. By applying cell isolation techniques, we obtained $>97 \%$ pure population of $\mathrm{CD} 11 \mathrm{C}^{+} \mathrm{Ly} 6 \mathrm{G}^{-}$cells that were $\mathrm{F} 4 / 80^{+}$, as determined by FACS, and $>90 \%$ pure population of $\mathrm{F} 4 / 80^{+}$

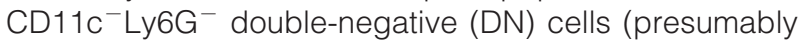


A
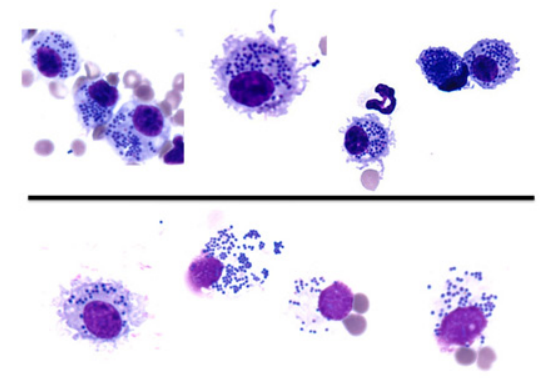

PCN

PBS
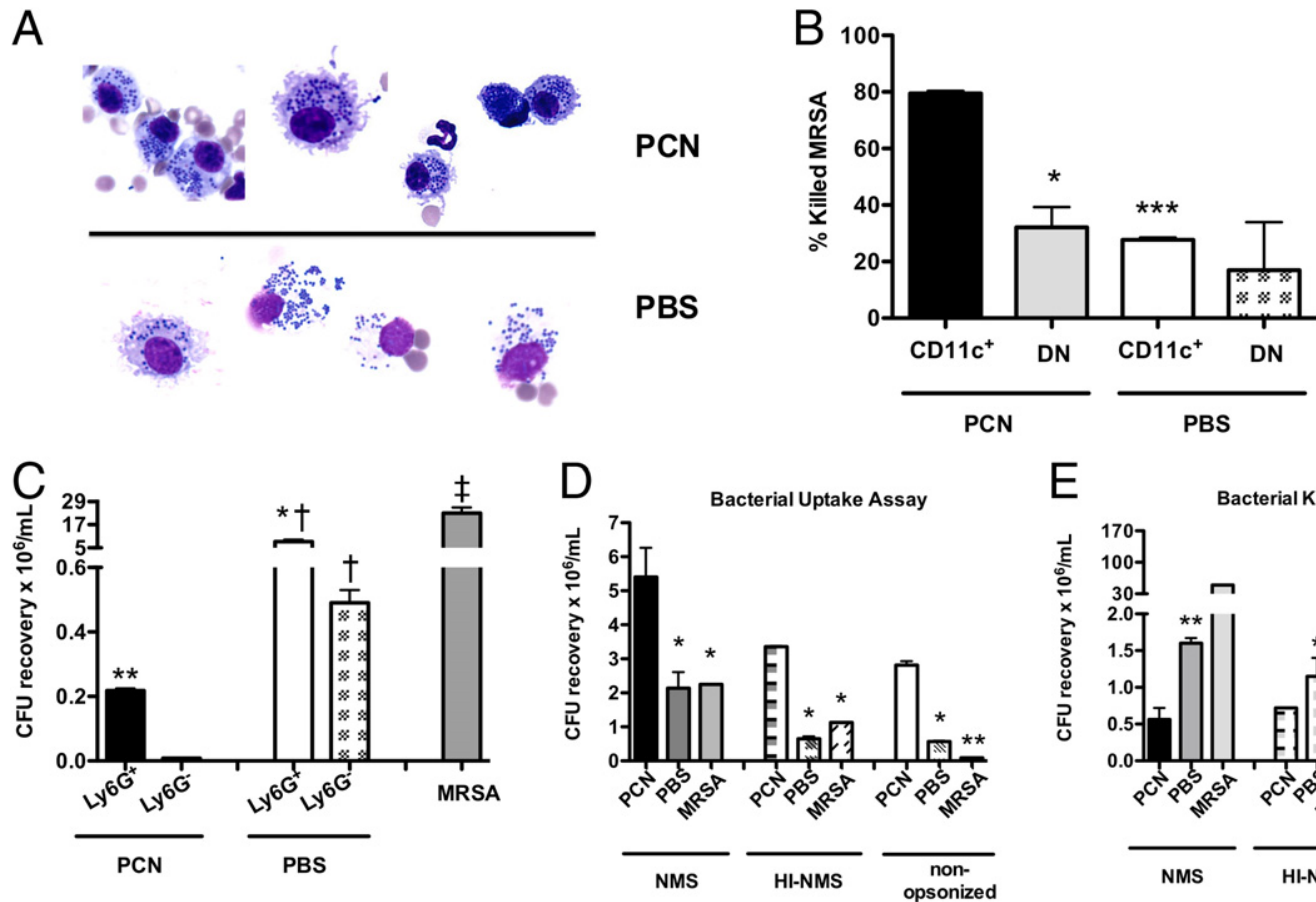

E
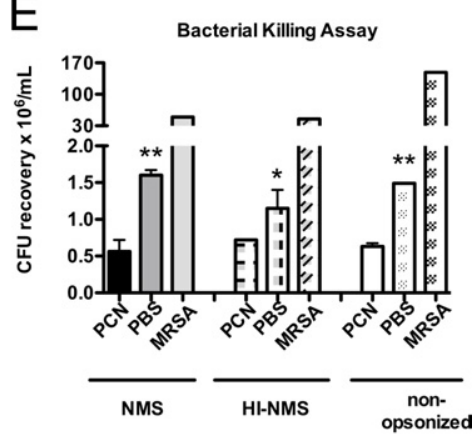

Figure 5. $\mathrm{CD}_{11 \mathrm{c}^{+}}$cells and neutrophils from PCN-dosed mice are more efficient in killing MRSA than the respective cells from PBS-dosed mice. A: Mice are dosed five times daily with PCN or PBS a week before MRSA infection. A micrograph of slide sections containing BALF cells isolated from PCN- or PBS-dosed mice 3 hours after MRSA infection. B: Mice are dosed with PCN or PBS and are sacrificed 1 week after the last dose. LHs are selected for CD $11 \mathrm{c}^{+}$cells and CD $11 \mathrm{C}^{-}$Ly6G ${ }^{-}$ (DN) cells by MACS columns. After selection, cells are incubated in a 1:1 ratio with MRSA for 1.5 hours, and CFUs are determined by plating on TSA plates, followed by an overnight incubation. The mean and SD of duplicate samples from three to four mice per group is shown. C: One week after the PCN or PBS dose, mice are infected with erythromycin-sensitive MRSA mutant, and 2.5 hours later, mice are sacrificed. LHs are selected for Ly6G ${ }^{+}$and ${\text {Ly } 6 \mathrm{G}^{-}}^{-}$cells that are incubated in a 1:1 ratio with WT MRSA for 3 hours. The CFUs of WT MRSA are determined after overnight incubation on TSA/erythromycin plates. D and E: Total BM cells isolated a week after the last PCN or PBS administration are plated in a 10:1 (D) or 1:1 (E) bacteria:BM cell ratio. The MRSA used for experiments is opsonized with NMS or heat-inactivated NMS or not opsonized. D: For the bacterial uptake assay, after a 30-minute incubation, gentamicin is added to each well to kill extracellular bacteria. The CFUs of bacteria taken up by BM cells are measured by plating. E: Bacterial killing by BM cells is assessed after a 3-hour incubation.

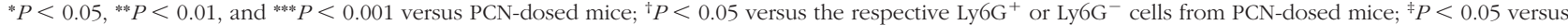
MRSA-only control. Experiments are performed at least twice, with a similar result.

inflammatory monocytes) from LHs of PCN- or PBSdosed but not infected mice (Figure 5B). Next, we investigated which of these cell subsets were better in killing MRSA. As expected, PCN-CD11 ${ }^{+}$cells were more efficient than DN cells in killing bacteria in vitro (killing efficacy of $\mathrm{CD}_{11 \mathrm{c}^{+}}$cells, approximately $80 \%$; DN cells, approximately 35\%; Figure 5B). Interestingly, no difference in bacterial killing was observed between CD11 ${ }^{+}$ and DN cells isolated from not infected PBS-dosed mice, and either of these cells killed only approximately $30 \%$ of bacteria. In the following experiment, we isolated $\mathrm{Ly}_{6 \mathrm{G}}{ }^{+}$ and $\mathrm{Ly}_{6 \mathrm{G}^{-}}$cells from the lungs of PCN- or PBS-dosed mice that, 2.5 hours earlier, were infected with erythromycin-sensitive MRSA. Similarly, when lung $\mathrm{Ly}_{6 \mathrm{G}}{ }^{+}$neutrophils and $\mathrm{Ly}_{6 \mathrm{G}^{-}}$cells isolated from erythromycin-MRSAinfected PCN- or PBS-dosed mice were examined for their ability to kill WT MRSA, both of these cell subsets from PCN-dosed mice were more effective in killing bacteria than the respective cell subsets from PBS-dosed mice (Figure $5 C)$. Moreover, ${\text { Ly } 6 G^{-}}^{-}$cells were better in killing MRSA than Ly6G $\mathrm{G}^{+}$cells in both experimental groups.

Within 1 hour after nasal installation, the PCN was found in respiratory lymph nodes (tracheobronchial and cervical) and, in 24 hours, they were nearly completely gone from the body. ${ }^{17}$ To determine whether PCN-mediated protection from MRSA infection was limited to the lung environment, we isolated BM cells from mice that had been dosed with PCN or PBS a week earlier. The BM cells were then incubated with MRSA to determine the efficiency of uptake and killing of bacteria in vitro. After 30 minutes of incubation, BM cells from PCN-dosed mice took up twofold more bacteria than BM cells from PBSdosed mice (Figure 5D). The rate of internalization was highest when bacteria were opsonized with NMS, although even unopsonized bacteria and bacteria opsonized with heat-inactivated NMS were also internalized and killed by BM cells from PCN-dosed mice (Figure 5, D and E). When compared with the background MRSA levels (bacteria incubated alone and treated with gentamicin), similar numbers of bacteria were retrieved from wells incubated with BM cells from PBS-dosed mice, indicating that, during the 30 minutes of incubation time, BM cells from PBS-dosed mice failed to efficiently take up MRSA (Figure 5D). Interestingly, after 3 hours of incubation, BM cells from PBS-dosed mice killed MRSA, although not as well as BM cells derived from PCN-dosed mice (Figure 5E). During the 3 hours of in vitro incubation, BM cells from PCN-dosed mice killed, on average, two to three times more bacteria than these cells from PBSdosed mice, and killing of MRSA by BM cells from PCNdosed mice was enhanced, although not fully dependent, on opsonization by complement (Figure 5E). 

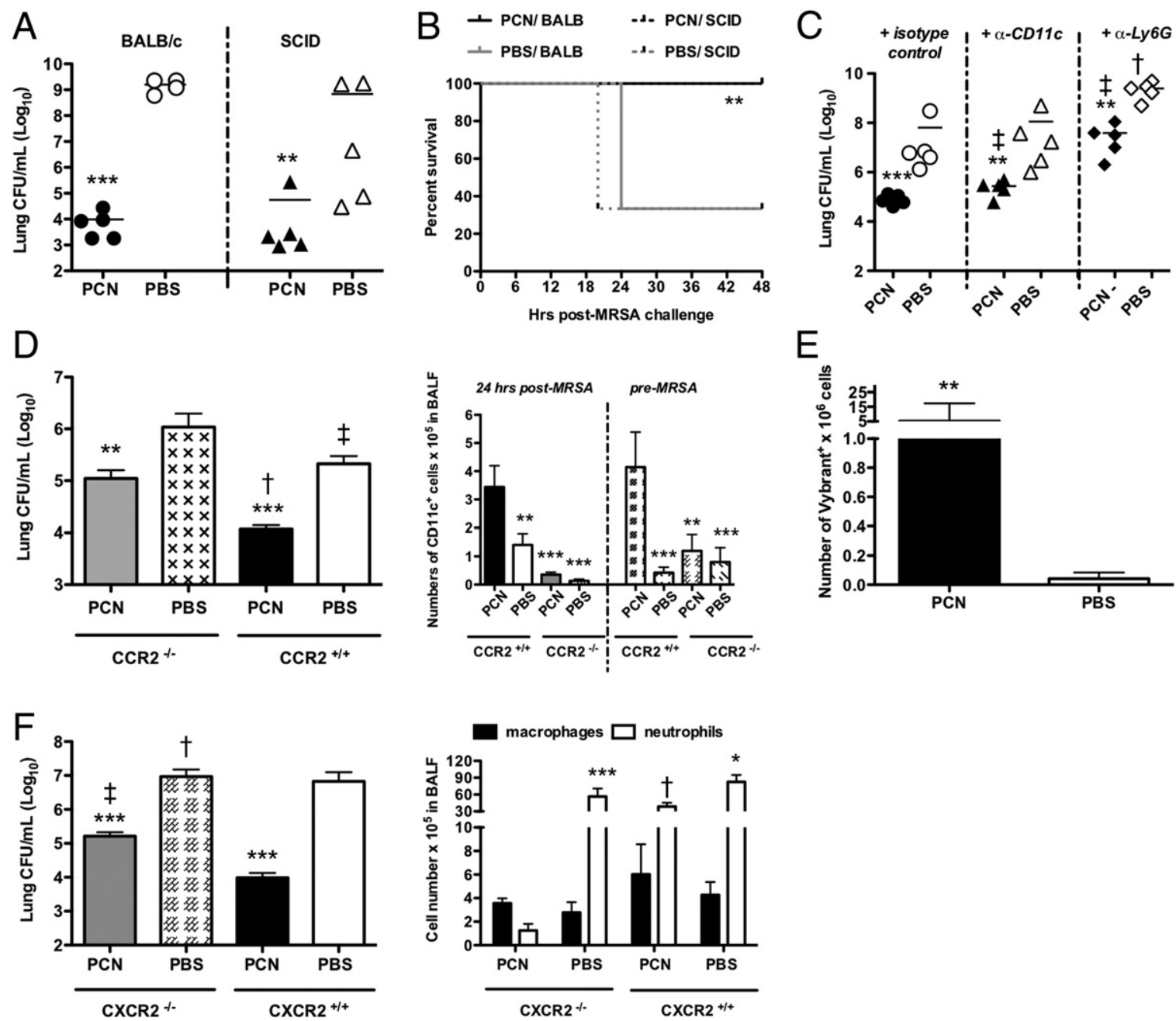

Figure 6. PCN-mediated protection against MRSA depends on innate immune cells. Mice are dosed five times daily with PCN or PBS a week before MRSA infection. A: The bacterial burden is evaluated in murine lungs 24 hours after infection. B: Survival is evaluated during a 2-day period. C: Mice are treated with anti-CD $11 \mathrm{c}$ mAb or anti-Ly $6 \mathrm{G}$ mAb on day $-3,-1$, and 0 , in relation to MRSA infection, and lung bacterial burden is evaluated 24 hours after infection. The results represent individual mice from one of two independent experiments. D: Mice are sacrificed 24 hours after infection. Bacterial burden in the lungs was determined (left panel), and numbers of CD11c ${ }^{+}$cells in BALF are determined by FACS after staining with fluorochrome-labeled anti-CD11c mAb before and after infection (right panel). The mean \pm SD of five mice per group is shown and represents the results of one of two independent experiments. E: At 1 hour after MRSA infection, mice are adoptively transferred with Vybrant-DiI-labeled naïve neutrophils, and 4 hours later, mice were sacrificed. The number of Vybrant ${ }^{+}$cells in the BALF is determined by FACS. The mean and SD of eight mice per group (combined two independent experiments) is shown. F: Mice are sacrificed 24 hours after infection. The bacterial burden in the lungs is determined (left panel), and numbers of polymorphonuclear and mononuclear cells in the BALF are determined by differential counts (right panel). The mean \pm SD of five mice per group is shown and represents the results of one of two independent experiments. ${ }^{*} P<0.05,{ }^{* * *} P<0.01,{ }^{* * * * *} P<0.001$ versus PBS-dosed mice; ${ }^{\dagger} P<0.001 ;{ }^{\ddagger} P<0.05$ versus PCN-dosed WT mice.

\section{PCN-Mediated Protection Against MRSA Is Independent of Adaptive Immunity}

We previously observed that the accelerated protection against viruses that was induced by PCN administration was dependent, in part, on the formation of iBALT, because the PCN administration to mice deficient in adaptive immunity, such as SCID, B-cell-deficient muMT, or WT mice depleted of CD4 T cells, did not prevent influenza infection. ${ }^{14}$ To discern whether $\mathrm{PCN}$ protection against MRSA also required functional adaptive immunity, PCN-dosed SCID mice were challenged with $5 \times$ $10^{7}$ CFUs of bacteria. SCID and WT mice dosed with PCN before infection showed a similar significant reduction in the lung bacterial burden at 24 and 48 hours after infection, when compared with their PBS-dosed litter- mates (Figure 6A and data not shown, respectively). In addition, $100 \%$ of PCN-dosed SCID and WT mice survived MRSA infection (Figure 6B), whereas only $40 \%$ of PBS-dosed SCID and WT mice survived to 24 hours after infection.

\section{Both Ly6G ${ }^{+}$Neutrophils and CD11C Cells Are Responsible for PCN-Mediated Protection from MRSA}

Although neutrophils are regarded to be the early and predominant cells responsible for fighting bacterial infections, including MRSA, ${ }^{49-51}$ increasing importance is assigned to $\mathrm{CD}_{11 \mathrm{C}^{+}}$cells $^{46}$ in such killing. To discriminate which groups of innate cells were responsible for PCN- 
mediated protection against MRSA, we depleted either $\mathrm{Ly}_{6 \mathrm{G}}{ }^{+}$(neutrophils) or CD11c cells (macrophages and DCs) from PCN-dosed mice on day $-3,-1$, and 0 , before MRSA infection. In mice dosed with PCN, depletion of either neutrophils or $\mathrm{CD} 11 \mathrm{c}^{+}$cells impaired resistance to infection, because the bacterial burdens in the lungs of depleted mice were significantly greater than the burdens in the lungs of PCN-dosed mice treated with isotype control Abs (Figure 6C, $P<0.05$ ). Moreover, in PCNdosed mice, neutrophil depletion resulted in much higher bacterial numbers than did CD11 $\mathrm{C}^{+}$cell depletion $(P<$ 0.05 ), indicating the importance of neutrophil function in $\mathrm{PCN}$-induced protection. Depletion of $\mathrm{CD}_{11 \mathrm{c}^{+}}$cells from PBS-dosed mice did not affect the lung CFU counts when compared with nondepleted PBS-dosed mice. However, the lungs of PBS-dosed mice depleted of neutrophils showed increases in CFUs when compared with PBSdosed mice not depleted of neutrophils $(P<0.001)$, indicating the importance of neutrophils in controlling MRSA, even in the absence of PCN. More important, regardless of whether the groups of mice were undepleted, depleted of neutrophils, or depleted of $\mathrm{CD}_{11 \mathrm{c}^{+}}$cells, the PCN-dosed mice were always more resistant to MRSA pneumonia than the PBS-dosed mice.

\section{Uncompromised Infiltration of Monocytes is Required for PCN-Mediated Protection Against MRSA}

Depletion of $\mathrm{CD}_{11 \mathrm{c}^{+}}$cells in PCN-dosed mice resulted in a partial inhibition of $\mathrm{PCN}$-induced protection against MRSA (Figure 6C). Whether the protective CD11 $\mathrm{C}^{+}$cells were recruited monocytes resulting from $\mathrm{PCN}$ treatment, PCN-altered resident macrophages, or PCN-altered recruited monocytes remained to be determined. CCR2 is a receptor molecule for $\mathrm{MCP}-1 .{ }^{52}$ Consequently, monocytes in CCR2 KO mice are impaired in their ability to infiltrate inflammatory sites and, thus, recruitment of monocytes in response to PCN treatment before MRSA infection should also be compromised. Indeed, numbers of $\mathrm{CD}_{11 \mathrm{C}^{+}}$cells were significantly reduced in PCNdosed CCR2 KO mice both before and 24 hours after MRSA infection when compared with PCN-dosed WT mice (Figure 6D). Also, PCN-dosed CCR2 KO mice were less competent than the PCN-dosed WT mice in clearing MRSA infection (Figure 6D). In this regard, at 24 hours after infection, PCN-dosed CCR2 KO mice showed $>10$ fold more bacteria in their lungs than PCN-dosed WT mice, indicating that CCR2 signaling played a role in PCN-induced resistance to MRSA. Interestingly, when compared with PBS-dosed WT mice, PBS-dosed CCR2 $\mathrm{KO}$ mice showed elevated bacterial burden, but reduced $\mathrm{CD}_{11 \mathrm{C}^{+}}$cell numbers, at 24 hours after infection, implicating the role of recruited monocytes in clearance of MRSA infection in these mice as well. All CCR2 KO mice, independent of treatment, survived MRSA infection up to 96 hours, when the study was terminated (see Supplemental Figure S5A at http://ajp.amjpathol.org). This suggested that absence of the CCR2 receptor had no effect on survival of PCN-dosed mice, and even improved the survival of PBS-dosed mice.

\section{PCN Enhances Neutrophil Trafficking into the Lungs in Response to MRSA Infection}

To determine whether administration of PCN enhanced neutrophil recruitment into the lungs, mice predosed with either PCN or PBS were infected with MRSA and, 1 hour later, adoptively transferred with Vybrant-Dil-labeled BM neutrophils isolated from naïve littermates. The number of Vybrant ${ }^{+}$cells in LHs of PCN-dosed mice 5 hours after MRSA infection was significantly higher when compared with the lungs of PBS-dosed mice (Figure 6E, $P<0.01$ ), indicating that PCN changed the lung environment, resulting in enhanced neutrophil recruitment in response to infection. Consistent with this observation were the findings of both a significant decrease of neutrophil recruitment in PCN-dosed CXCR2 KO mice (Figure 6F, $P<$ 0.001 ) and lower effectiveness in clearing MRSA infection $(P<0.05)$ compared with PCN-dosed WT mice. Moreover, the inability of PCN-dosed CXCR2 KO mice to recruit neutrophils to MRSA-infected lungs decreased their survival compared with PCN-dosed WT mice. In this regard, the PCN-dosed $\mathrm{KO}$ mice started dying by day 4 after infection; and by 5 days after infection, $>80 \%$ of PCN-dosed CXCR2 KO mice had succumbed to MRSA infection, whereas all of the PCN-treated WT mice survived through 5 days (see Supplemental Figure S5B at http://ajp.amjpathol.org). More important, when compared with PCN-dosed CXCR2 KO mice, PBS-dosed CXCR2 KO mice were less effective in clearing MRSA infection, despite the CXCR2-independent recruitment of neutrophils to the lungs of PBS-dosed CXCR2 KO mice, but PCN- and PBS-dosed KO mice showed a similar lethality rate. This suggested that CXCR2 signaling was important for $\mathrm{PCN}$-induced protection against lethality from MRSA infection, but not important for the PCN-independent resistance to MRSA pneumonia.

\section{IL-13 Is Required for PCN-Mediated Protection Against MRSA}

We found that levels of IL-13 were significantly elevated in the BALF of PCN-dosed mice up to 9 hours after MRSA infection (Figure 2D). To determine whether anti-inflammatory cytokines played an important role in PCN-mediated protection against MRSA, we analyzed bacterial burden in the lungs of PBS- or PCN-dosed IL-13 and IL-4 $\mathrm{KO}$ mice 24 hours after infection. Interestingly, no difference in bacterial clearance from the lungs was observed between PCN- and PBS-dosed IL-13 KO and PBS-dosed WT mice, but when those three groups of mice were compared with PCN-dosed WT mice, the three groups of mice each had at least 100-fold more bacteria in their lungs (Figure 7A). Consistent with the lack of bacterial clearance, PCN-dosed IL-13 KO mice reached $50 \%$ mortality within the first 24 hours after MRSA infection (see Supplemental Figure S5C at http://ajp.amjpathol.org). PCN-dosed IL-4 KO mice cleared bacteria more effi- 

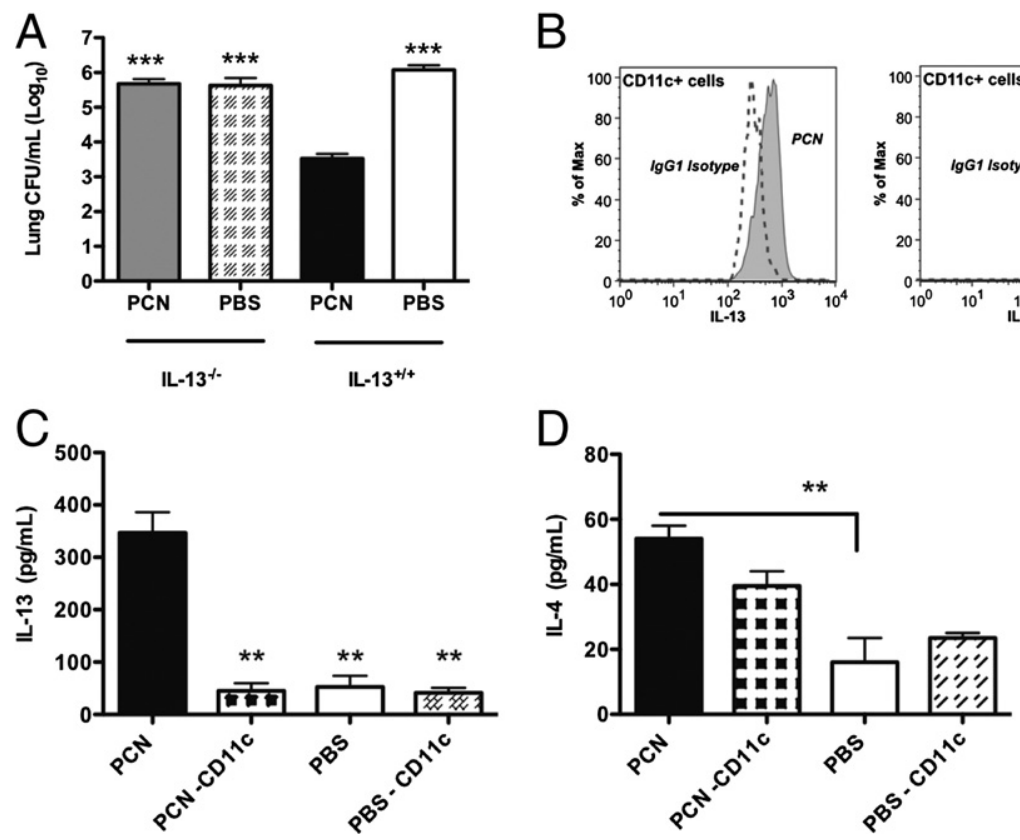

B
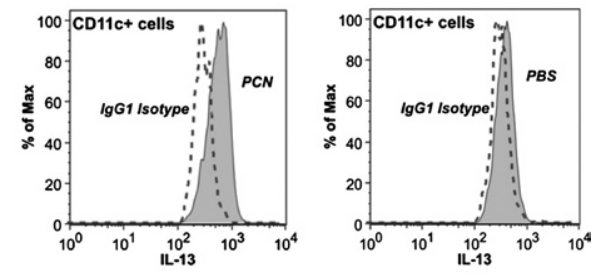

Figure 7. $\mathrm{CD}_{11 \mathrm{c}^{+}}$cell-induced early IL-13 secretion is important for disease resolution by PCN-dosed mice. A: Mice are dosed five times daily with PCN or PBS a week before MRSA infection and sacrificed 24 hours after infection. The bacterial burden in lungs is determined. $\mathbf{B}$ : PCN- and PBS-dosed mice are infected with $1 \times$ $10^{8}$ CFUs of MRSA. FACS staining is performed on cells isolated from the BALF of these mice 2.5 hours after MRSA infection. Representative plots of $\mathrm{IL}-13^{+} \mathrm{CD} 11 \mathrm{c}^{+}$cells are shown compared with these $\mathrm{CD} 11 \mathrm{c}^{+}$cells stained with isotype control Abs. C and D: Mice are depleted of $\mathrm{CD} 11 \mathrm{C}^{+}$cells on day $-3,-1$, and 0 , in relation to MRSA infection, as described in the legend for Figure 6C. Mice are sacrificed 4 hours after infection, and the concentration of IL-13 (C) and IL-4 (D) is determined in their cell-free BALF. Each experiment is performed twice. The mean $\pm \mathrm{SD}$ of three to four mice per group from a single experiment is shown. ${ }^{*} P<0.01,{ }^{* * * k *} P<0.001$ versus PCN-dosed mice. ciently than PCN-dosed IL-13 KO mice, but not nearly as well as PCN-dosed WT mice (data not shown). We also found that $\mathrm{CD}_{11 \mathrm{C}^{+}}$cells in PCN-dosed mice produced IL-13 at 2.5 hours after MRSA infection (Figure 7B). This observation was further confirmed by the virtual absence of IL-13 in BALFs of PCN-dosed WT mice that, before infection, were depleted of CD11 ${ }^{+}$cells, much like PBSdosed mice independent of the presence of CD11C ${ }^{+}$ cells (Figure 7C). When tested, IL-4 levels were significantly elevated in PCN-dosed undepleted mice, when compared with PBS-dosed mice either depleted or not depleted of CD11C ${ }^{+}$cells (Figure 7D).

\section{Discussion}

We show herein that intranasal delivery of VLPS, such as PCN, induced near complete resistance to lethal MRSA pneumonia. Mice dosed with PCN either before or shortly after MRSA infection were protected from mortality and showed up to a millionfold reduction in bacterial burden, when compared with PBS-dosed mice. Remarkably, when mice were treated with a VLP unrelated to PCN, P22, a similar degree of protection and recovery was observed. This suggests that the protective effect induced by either of the VLPs can be attributed to shared physical characteristics, such as repeating protein subunits, and small size, similar to a virus, rather than the origin of the VLP. VLPS, because of their ability to stimulate pathogen-associated molecular pattern recognition receptors on DCs, are effective inducers of innate, and adaptive, immunity. ${ }^{18-20,53}$ Thus, VLPS have been used predominantly for their adjuvant properties ${ }^{19,21}$ and their ability to deliver either genetically conjugated or chemically fused epitopes for the induction of specific immune responses. ${ }^{25,54}$ However, their potential role as self-proprietors of immune modulation has not been extensively investigated, and the present data suggest that they could be used in this regard.
Because of the early resolution of MRSA infection by more efficient neutrophils and macrophages in PCNdosed mice, decreased signs of cellular damage (measured by extracellular release of LDH) or tissue leaking (measured by serum albumin level) were found in the BALF of PCN-dosed mice. In contrast to PCN-dosed mice, levels of albumin and LDH in the BALF of PBSdosed mice increased as early as 6 and 12 hours after MRSA infection, respectively. These increases coincided with inefficient bacterial clearance in the lungs of PBSdosed mice by infiltrating neutrophils and mononuclear cells, which, as early as 2 to 3 hours after infection, showed signs of necrosis and extracellular release of bacteria. At 6 hours after infection, lung bacterial burden was similar in PCN- and PBS-dosed mice; thus, in PCNdosed mice, the host response to MRSA caused less lung damage, which is similar to what we found in PCNdosed mice infected with influenza. ${ }^{14}$ The more efficient bacterial clearance and abridged lung damage coincided with the greatly reduced lung tissue pathological characteristics, apparent by the lack of congestion and interstitial edema at 20 hours after MRSA infection in the lungs of PCN-dosed, but not PBS-dosed, mice.

Up to 12 hours after MRSA infection, most cells in the BALF of PBS-dosed mice could be classified as macrophages, based on their expression of SiglecF and intermediate levels of $\mathrm{MHCll}$. However, in PCN-dosed mice at these time points, SiglecF ${ }^{-} / \mathrm{MHClI}^{\text {high }} \mathrm{DCs}$ accounted for slightly $>10 \%$ of $\mathrm{CD}_{11 \mathrm{c}^{+}}$cells. The role of $\mathrm{CD} 11 \mathrm{c}^{+}$cells in pulmonary MRSA infections just recently gained attention. ${ }^{46}$ According to the study by Martin et al, ${ }^{46}$ clodronate-induced depletion of $\mathrm{CD}_{11 \mathrm{C}^{+}}$AMs did not affect bacterial burden in the lungs, but was associated with increased mortality; however, when $\mathrm{CD}_{11 \mathrm{C}^{+}}$cells were depleted in CD11c-enhanced green fluorescence protein-diphtheria toxin mice, the bacterial burden in the lungs increased, although no changes in mortality were 
observed. In this regard, it is plausible that PCN-induced CD11 $\mathrm{c}^{+}$DCs, although not numerous in the BALF, are important for protection from MRSA pneumonia.

The altered phagocytosis of apoptotic cells in the lung has been linked to the overwhelming inflammation that can lead to extensive tissue damage and even autoimmunity. ${ }^{55}$ Not surprisingly, one of the survival mechanisms exploited by intracellular bacteria includes reprogramming of the phagocytic cells, which allows them to escape intracellular killing. In this regard, Mtb was shown to avoid killing by macrophages via induction of cell necrosis rather than apoptosis. ${ }^{56}$ Also, MRSA-induced programmed necrosis rapidly killed neutrophils, but not bacteria. ${ }^{57}$ In our experiments, as early as 2 to 3 hours after MRSA infection, mononuclear cells isolated from PCN-dosed mice were intact and associated with bacteria. At the same time after infection, the plasma membrane of macrophages from PBS-dosed mice was already destroyed, and the remaining cell debris showed signs of organelle swelling, all of which is usually associated with necrosis. Furthermore, in contrast to PCNdosed mice, extracellular portions of the BALF of PBSdosed mice contained numerous bacteria, suggesting inefficient killing by cells in PBS-dosed mice. These results implicate that lung macrophages in PCN-dosed mice were resistant to MRSA-induced necrosis and, thus, were better able to kill MRSA.

Enhancement of the primary immune response is responsible for $\mathrm{PCN}$-induced protection against body weight loss and reduction of viral titers in the lungs of mice infected with either murine influenza or severe acute respiratory syndrome viruses. ${ }^{14}$ Herein, we report that PCN-mediated protection against MRSA infection was entirely dependent on functional innate immunity. In this regard, PCN-dosed SCID mice showed similar recovery rates and nearly identical reduction of bacterial burden as PCN-dosed WT mice, and depletion of CD4 or CD8 T cells even further enhanced PCN-mediated protection (data not shown). Moreover, when depleted of either neutrophils or $\mathrm{CD}_{11 \mathrm{C}^{+}}$cells, $\mathrm{PCN}$-dosed mice were less resistant to MRSA pneumonia. However, depletion of neutrophils after PCN administration resulted in the loss of more than two logs of protection and increased mortality of mice, whereas CD11c depletion resulted in the loss of less than a log of protection and had no effect on mouse survival. There is an obvious inconsistency between how efficient CD11c cells from PCN-dosed mice were in killing MRSA in vitro and only a moderate effect that the depletion of these cells had on bacterial burden in PCN-dosed mice in vivo. This discrepancy could be attributed to the overall fewer macrophages in the lungs when compared with neutrophils in PCN-dosed mice. Therefore, although $\mathrm{CD} 11 \mathrm{c}^{+}$cells appear more efficient in killing MRSA in vitro, neutrophils may have a greater in vivo effect because of their prevalence in the MRSAinfected lung.

CCR2 is a receptor molecule for MCP-1; therefore, the trafficking of monocytes to inflammatory sites is compromised in CCR2 $\mathrm{KO}$ mice. ${ }^{52}$ Even before MRSA infection, the numbers of $\mathrm{CD}_{11 \mathrm{C}^{+}}$cells in CCR2 $\mathrm{KO}$ mice dosed with PCN were significantly lower than the numbers of these cells in PCN-dosed WT mice, and were similar to the numbers of $\mathrm{CD}_{11 \mathrm{c}^{+}}$cells in PBS-dosed WT and CCR2 KO mice. At 24 hours after MRSA infection, the bacterial burden of CCR2-deficient PCN-dosed mice was significantly elevated when compared with PCN-dosed WT mice, which is consistent with the well-established importance of recruited monocytes in fighting pulmonary microbial infections. ${ }^{7,52,58}$ Therefore, we concluded that many $\mathrm{CD} 11 \mathrm{c}^{+}$cells in the lungs of PCN-dosed mice at infection are newly recruited resident cells. Despite sharing a similar FACS profile with $\mathrm{CD}_{11 \mathrm{C}^{+}}$cells in PBS-dosed mice, these cells were recruited to the lung in response to PCN administration; thus, they represent a diverse cell population, perhaps one that is more efficient in fighting bacterial infection.

Neutrophils are considered the primary line of defense against MRSA infections, ${ }^{49,59}$ although they are also actively targeted by MRSA to improve its survival within the host. 57,60,61 In our experiments, PCN-dosed WT mice showed enhanced neutrophil recruitment, but also a much faster decline in neutrophil numbers in the MRSAinflamed lung, which presumably prevented extensive tissue damage. However, PCN-dosed CXCR2 KO mice infected with MRSA showed increased bacterial burden at 24 hours after infection, increased mortality, and a deficiency of neutrophil recruitment when compared with PCN-dosed WT mice. In contrast, CXCR2 KO mice that received PBS had nearly identical numbers of neutrophils as PBS-dosed WT mice. This suggests that, in contrast to PBS-dosed mice, MRSA-induced recruitment of neutrophils in PCN-dosed mice was CXCR2 dependent. Because no difference in bacterial burden was observed between PBS-dosed CXCR2 KO and WT mice at 24 hours after infection, we concluded, in agreement with other studies, ${ }^{57,61}$ that neutrophils alone are not sufficient in clearing MRSA infection.

Among the $\mathrm{CD} 11 \mathrm{C}^{+} \mathrm{F} 4 / 80^{+}$cells isolated from PCNdosed MRSA-infected mice, the high ratio of M1

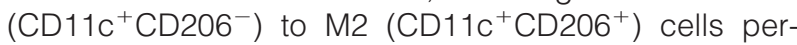
sisted throughout the disease. In contrast to these mice, most macrophages in MRSA-infected, PBS-dosed mice showed characteristics of M2 cells. It is well described that M1 macrophages are more efficient responders to an acute infection, whereas the long-term stage M2 cells, even though they cause less tissue damage, are also less efficient in killing microbes. ${ }^{62}$ Furthermore, M2 macrophages can be subdivided into three subclasses (a to c), in which M2a cells develop in the presence of IL-13/L-4 and lipopolysaccharide enhances the M2b phenotype. ${ }^{63}$ M2a AMs supported M1 cells and promoted lung defense against Pneumocystis murina. ${ }^{64}$ Interestingly, induction of IL-13 and IL-4 was observed early after MRSA infection of PCN-dosed, but not PBS-dosed, mice, suggesting that $\mathrm{M} 2$ cells in PCN- and PBS-dosed mice can differ in their ability to support M1 cells in response to MRSA infection. Despite the presence of IL-13 in the BALF of MRSA-infected PCN-dosed, but not PBS-dosed, mice, the levels of proinflammatory cytokines remained similar between these mice until 12 hours after infection. After 12 hours of infection and likely as a consequence of disease resolution in PCN-dosed mice, a sudden reduc- 
tion of proinflammatory cytokines occurred in these mice. The importance of IL-13 in PCN-mediated protection from lethal MRSA pneumonia was indicated by the lack of recovery and disease resolution in PCN-dosed IL-13 KO mice, the increased mortality of these mice, and the realization of only partial protection in PCN-dosed IL-4 KO mice (data not shown). IL-13 causes neutrophil activation and recruitment via induction of IL-8-like chemoattractant on airway epithelium. ${ }^{65,66}$ The role of IL-13 in pulmonary clearance of methicillin-sensitive $S$. aureus was reported by Olszewski et al. ${ }^{67}$ In their hands, IL-13 KO mice showed delayed clearance of bacteria, but when mice were reconstituted with exogenous IL-13, normal clearance was restored. We have determined that $\mathrm{CD} 11 \mathrm{C}^{+}$ cells in PCN-dosed, but not in PBS-dosed, mice are accountable for the production of IL-13, whereas the production of IL-4 was only partially dependent on the presence of $\mathrm{CD} 11 \mathrm{C}^{+}$cells. Which subsets of PCN-induced CD $11 \mathrm{C}^{+}$cells are involved in IL-13 and/or IL-4 production, and the exact mechanism of $\mathrm{IL}-13-$ dependent protection in our model, requires further investigation.

In summary, this work describes a novel approach of priming of the lungs via administration of noninfectious VLPs, resulting in enhanced efficacy of the innate immune response, but omits the risk of tissue-damaging inflammation that occurs with pathogen-induced alteration of lung environment. Our results indicate that improved uptake and killing of MRSA by neutrophils and $\mathrm{CD}_{11 \mathrm{C}^{+}}$cells, and possibly cell-independent mechanisms, are involved. To our knowledge, this is the first report describing the importance of $\mathrm{CD} 11 \mathrm{C}^{+}$cells in IL-13-dependent protection from MRSA pneumonia. Our results provide important insights into the mechanisms of host anti-MRSA response in the lung and suggest that VLPS could be a viable means of enhancing these mechanisms.

\section{Acknowledgments}

We thank members of the Harmsen and Voyich laboratories (Montana State University) for their assistance in performing the described assays and Amy Servid from the Douglas laboratory (Montana State University) for preparation of P22 VLPS.

\section{References}

1. Walzl G, Tafuro S, Moss P, Openshaw PJ, Hussell T: Influenza virus lung infection protects from respiratory syncytial virus-induced immunopathology. J Exp Med 2000, 192:1317-1326

2. Folkerts G, Walzl G, Openshaw PJ: Do common childhood infections "teach" the immune system not to be allergic? Immunol Today 2000, $21: 118-120$

3. Chen HD, Fraire AE, Joris I, Brehm MA, Welsh RM, Selin LK: Memory CD8 + T cells in heterologous antiviral immunity and immunopathology in the lung. Nat Immunol 2001, 2:1067-1076

4. Chen HD, Fraire AE, Joris I, Welsh RM, Selin LK: Specific history of heterologous virus infections determines anti-viral immunity and immunopathology in the lung. Am J Pathol 2003, 163:1341-1355

5. Walzl G, Humphreys IR, Marshall BG, Edwards L, Openshaw PJ, Shaw RJ, Hussell T: Prior exposure to live Mycobacterium bovis BCG decreases Cryptococcus neoformans-induced lung eosinophilia in a gamma interferon-dependent manner. Infect Immun 2003, 71:33843391
6. Williams AE, Edwards L, Hussell T: Colonic bacterial infection abrogates eosinophilic pulmonary disease. J Infect Dis 2006, 193:223230

7. Wissinger E, Goulding J, Hussell T: Immune homeostasis in the respiratory tract and its impact on heterologous infection. Semin Immunol 2009, 21:147-155

8. Edwards L, Williams AE, Krieg AM, Rae AJ, Snelgrove RJ, Hussell T: Stimulation via Toll-like receptor 9 reduces Cryptococcus neoformans-induced pulmonary inflammation in an IL-12-dependent manner. Eur J Immunol 2005, 35:273-281

9. Williams AE, Edwards L, Humphreys IR, Snelgrove R, Rae A, Rappuoli R, Hussell T: Innate imprinting by the modified heat-labile toxin of Escherichia coli (LTK63) provides generic protection against lung infectious disease. J Immunol 2004, 173:7435-7443

10. Watkins AC, Caputo FJ, Badami C, Barlos D, Xu da Z, Lu Q, Feketeova E, Deitch EA: Mesenteric lymph duct ligation attenuates lung injury and neutrophil activation after intraperitoneal injection of endotoxin in rats. J Trauma 2008, 64:126-130

11. Wang J, Barke RA, Charboneau R, Schwendener R, Roy S: Morphine induces defects in early response of alveolar macrophages to Streptococcus pneumoniae by modulating TLR9-NF-kappa B signaling. J Immunol 2008, 180:3594-3600

12. Droemann D, Goldmann T, Tiedje T, Zabel P, Dalhoff K, Schaaf B: Toll-like receptor 2 expression is decreased on alveolar macrophages in cigarette smokers and COPD patients. Respir Res 2005, 6:68

13. Chen H, Cowan MJ, Hasday JD, Vogel SN, Medvedev AE: Tobacco smoking inhibits expression of proinflammatory cytokines and activation of IL-1R-associated kinase, p38, and NF-kappaB in alveolar macrophages stimulated with TLR2 and TLR4 agonists. J Immunol 2007, 179:6097-6106

14. Wiley JA, Richert LE, Swain SD, Harmsen A, Barnard DL, Randall TD, Jutila M, Douglas T, Broomell C, Young M, Harmsen AG: Inducible bronchus-associated lymphoid tissue elicited by a protein cage nanoparticle enhances protection in mice against diverse respiratory viruses. PLoS One 2009, 4:e7142

15. Rangel-Moreno J, Hartson L, Navarro C, Gaxiola M, Selman M, Randall TD: Inducible bronchus-associated lymphoid tissue (BALT) in patients with pulmonary complications of rheumatoid arthritis. J Clin Invest 2006, 116:3183-3194

16. Flenniken ML, Willits DA, Harmsen AL, Liepold LO, Harmsen AG, Young MJ, Douglas T: Melanoma and lymphocyte cell-specific targeting incorporated into a heat shock protein cage architecture. Chem Biol 2006, 13:161-170

17. Kaiser CR, Flenniken ML, Gillitzer E, Harmsen AL, Harmsen AG, Jutila MA, Douglas T, Young MJ: Biodistribution studies of protein cage nanoparticles demonstrate broad tissue distribution and rapid clearance in vivo. Int $\mathrm{J}$ Nanomedicine 2007, 2:715-733

18. Jennings GT, Bachmann MF: The coming of age of virus-like particle vaccines. Biol Chem 2008, 389:521-536

19. Lechmann M, Murata K, Satoi J, Vergalla J, Baumert TF, Liang TJ: Hepatitis C virus-like particles induce virus-specific humoral and cellular immune responses in mice. Hepatology 2001, 34:417-423

20. Zhang S, Liang M, Gu W, Li C, Miao F, Wang X, Jin C, Zhang L, Zhang $F$, Zhang $Q$, Jiang L, Li M, Li D: Vaccination with dengue virus-like particles induces humoral and cellular immune responses in mice. Virol J 2011, 8:333

21. Velasquez LS, Shira S, Berta AN, Kilbourne J, Medi BM, Tizard I, Ni Y, Arntzen CJ, Herbst-Kralovetz MM: Intranasal delivery of Norwalk virus-like particles formulated in an in situ gelling, dry powder vaccine. Vaccine 2011, 29:5221-5231

22. Herbst-Kralovetz M, Mason HS, Chen Q: Norwalk virus-like particles as vaccines. Expert Rev Vaccines 2010, 9:299-307

23. Barr E, Sings HL: Prophylactic HPV vaccines: new interventions for cancer control. Vaccine 2008, 26:6244-6257

24. Harper DM: Currently approved prophylactic HPV vaccines. Expert Rev Vaccines 2009, 8:1663-1679

25. Chackerian B, Rangel M, Hunter Z, Peabody DS: Virus and virus-like particle-based immunogens for Alzheimer's disease induce antibody responses against amyloid-beta without concomitant $\mathrm{T}$ cell responses. Vaccine 2006, 24:6321-6331

26. Fulurija A, Lutz TA, Sladko K, Osto M, Wielinga PY, Bachmann MF, Saudan P: Vaccination against GIP for the treatment of obesity. PLoS One 2008, 3:e3163 
27. Klevens RM, Morrison MA, Nadle J, Petit S, Gershman K, Ray S, Harrison LH, Lynfield R, Dumyati G, Townes JM, Craig AS, Zell ER, Fosheim GE, McDougal LK, Carey RB, Fridkin SK: Invasive methicillin-resistant Staphylococcus aureus infections in the United States. JAMA 2007, 298:1763-1771

28. Boucher HW, Corey GR: Epidemiology of methicillin-resistant Staphylococcus aureus. Clin Infect Dis 2008, 46(Suppl 5):S344-S349

29. Miller LS, Cho JS: Immunity against Staphylococcus aureus cutaneous infections. Nat Rev Immunol 2011, 11:505-518

30. Graves SF, Kobayashi SD, DeLeo FR: Community-associated methicillin-resistant Staphylococcus aureus immune evasion and virulence. J Mol Med (Berl) 2010, 88:109-114

31. Deleo FR, Otto M, Kreiswirth BN, Chambers HF: Community-associated methicillin-resistant Staphylococcus aureus. Lancet 2010, 375: 1557-1568

32. Francis JS, Doherty MC, Lopatin U, Johnston CP, Sinha G, Ross T, Cai M, Hansel NN, Perl T, Ticehurst JR, Carroll K, Thomas DL, Nuermberger E, Bartlett JG: Severe community-onset pneumonia in healthy adults caused by methicillin-resistant Staphylococcus aureus carrying the Panton-Valentine leukocidin genes. Clin Infect Dis 2005, 40:100-107

33. Boles BR, Thoendel M, Roth AJ, Horswill AR: Identification of genes involved in polysaccharide-independent Staphylococcus aureus biofilm formation. PLoS One 2010, 5:e10146

34. Siemen DW, Schepetkin IA, Kirpotina LN, Lei B, Quinn MT: Neutrophil Isolation from Nonhuman Species. Methods in Molecular Biology 2007, 412:21-34

35. Voyich JM, Braughton KR, Sturdevant DE, Whitney AR, Said-Salim B, Porcella SF, Long RD, Dorward DW, Gardner DJ, Kreiswirth BN, Musser JM, DeLeo FR: Insights into mechanisms used by Staphylococcus aureus to avoid destruction by human neutrophils. J Immunol 2005, 175:3907-3919

36. Prevelige PEJ: The Bacteriophages. Edited by Calendar, R. New York, Oxford University Press, 2005, pp 457-468

37. Steinmetz NF, Manchester M. Overview of the manifold VNPs used in nantechnology. Viral Nonoparticles: Tools for Material Science and Biomedicine, vol 1, ed 1, ch 2. Edited by M Manchester. Singapore, Pan Stanford Publishing Pte. Ltd., 2011, pp 13-48

38. Sonozaki H, Cohen S: The macrophage disappearance reaction: mediation by a soluble Iymphocyte-derived factor. Cell Immunol 1971, 2:341-352

39. Gu J, Zuo J, Lei L, Zhao H, Sun C, Feng X, Du C, Li X, Yang Y, Han W: LysGH15 reduces the inflammation caused by lethal methicillinresistant Staphylococcus aureus infection in mice. Bioeng Bugs 2011, 2:96-99

40. Watkins RL, Pallister KB, Voyich JM: The SaeR/S gene regulatory system induces a pro-inflammatory cytokine response during Staphylococcus aureus infection. PLoS One 2011, 6:e19939

41. Goulding J, Snelgrove R, Saldana J, Didierlaurent A, Cavanagh M, Gwyer E, Wales J, Wissinger EL, Hussell T: Respiratory infections: do we ever recover? Proc Am Thorac Soc 2007, 4:618-625

42. Kugathasan K, Roediger EK, Small CL, McCormick S, Yang P, Xing Z: $\mathrm{CD} 11 \mathrm{c}+$ antigen presenting cells from the alveolar space, lung parenchyma and spleen differ in their phenotype and capabilities to activate naive and antigen-primed T cells. BMC Immunol 2008, 9:48

43. Fei M, Bhatia S, Oriss TB, Yarlagadda M, Khare A, Akira S, Saijo S, Iwakura Y, Fallert Junecko BA, Reinhart TA, Foreman O, Ray P, Kolls $J$, Ray A: TNF-alpha from inflammatory dendritic cells (DCs) regulates lung IL-17A/L-5 levels and neutrophilia versus eosinophilia during persistent fungal infection. Proc Natl Acad Sci U S A 2011, 108:5360-5365

44. Sung SS, Fu SM, Rose CE Jr, Gaskin F, Ju ST, Beaty SR: A major lung CD103 (alphaE)-beta7 integrin-positive epithelial dendritic cell population expressing Langerin and tight junction proteins. J Immunol 2006, 176:2161-2172

45. Kim TS, Braciale TJ: Respiratory dendritic cell subsets differ in their capacity to support the induction of virus-specific cytotoxic CD8+ T cell responses. PLoS One 2009, 4:e4204

46. Martin FJ, Parker D, Harfenist BS, Soong G, Prince A: Participation of $\mathrm{CD} 11 \mathrm{c}+$ leukocytes in methicillin-resistant Staphylococcus aureus clearance from the lung. Infect Immun 2011, 79:1898-1904

47. Mosser DM, Edwards JP: Exploring the full spectrum of macrophage activation. Nat Rev Immunol 2008, 8:958-969
48. Wojcik AJ, Skaflen MD, Srinivasan S, Hedrick CC: A critical role for ABCG1 in macrophage inflammation and lung homeostasis. J Immunol 2008, 180:4273-4282

49. Robertson CM, Perrone EE, McConnell KW, Dunne WM, Boody B, Brahmbhatt T, Diacovo MJ, Van Rooijen N, Hogue LA, Cannon CL, Buchman TG, Hotchkiss RS, Coopersmith CM: Neutrophil depletion causes a fatal defect in murine pulmonary Staphylococcus aureus clearance. J Surg Res 2008, 150:278-285

50. Senavsky C, Craft N, Miller LS: Bacterial Infections. Edited by AA Gaspary, SK Tyring. Springer, London, UK, 2008, pp 335-363

51. Heyworth PG, Cross AR, Curnutte JT: Chronic granulomatous disease. Curr Opin Immunol 2003, 15:578-584

52. Boring L, Gosling J, Chensue SW, Kunkel SL, Farese RV Jr, Broxmeyer HE, Charo IF: Impaired monocyte migration and reduced type 1 (Th1) cytokine responses in C-C chemokine receptor 2 knockout mice. J Clin Invest 1997, 100:2552-2561

53. Lenz P, Day PM, Pang YY, Frye SA, Jensen PN, Lowy DR, Schiller JT: Papillomavirus-like particles induce acute activation of dendritic cells. J Immunol 2001, 166:5346-5355

54. Lacasse P, Denis J, Lapointe R, Leclerc D, Lamarre A: Novel plant virus-based vaccine induces protective cytotoxic T-lymphocyte-mediated antiviral immunity through dendritic cell maturation. J Virol 2008, 82:785-794

55. Jennings JH, Linderman DJ, Hu B, Sonstein J, Curtis JL: Monocytes recruited to the lungs of mice during immune inflammation ingest apoptotic cells poorly. Am J Respir Cell Mol Biol 2005, 32:108-117

56. Behar SM, Martin CJ, Booty MG, Nishimura T, Zhao X, Gan HX, Divangahi M, Remold HG: Apoptosis is an innate defense function of macrophages against Mycobacterium tuberculosis. Mucosal Immunol 2011, 4:279-287

57. Kobayashi SD, Braughton KR, Palazzolo-Ballance AM, Kennedy AD, Sampaio E, Kristosturyan E, Whitney AR, Sturdevant DE, Dorward DW, Holland SM, Kreiswirth BN, Musser JM, DeLeo FR: Rapid neutrophil destruction following phagocytosis of Staphylococcus aureus. J Innate Immun 2010, 2:560-575

58. Skold M, Behar SM: Tuberculosis triggers a tissue-dependent program of differentiation and acquisition of effector functions by circulating monocytes. J Immunol 2008, 181:6349-6360

59. Cheung GY, Rigby K, Wang R, Queck SY, Braughton KR, Whitney AR, Teintze M, DeLeo FR, Otto M: Staphylococcus epidermidis strategies to avoid killing by human neutrophils. PLoS Pathog 2010, 6:e1001133

60. Diep BA, Chan L, Tattevin P, Kajikawa O, Martin TR, Basuino L, Mai TT, Marbach H, Braughton KR, Whitney AR, Gardner DJ, Fan X, Tseng CW, Liu GY, Badiou C, Etienne J, Lina G, Matthay MA, DeLeo FR, Chambers HF: Polymorphonuclear leukocytes mediate Staphylococcus aureus Panton-Valentine leukocidin-induced lung inflammation and injury. Proc Natl Acad Sci U S A 2010, 107:5587-5592

61. Gresham HD, Lowrance JH, Caver TE, Wilson BS, Cheung AL, Lindberg FP: Survival of Staphylococcus aureus inside neutrophils contributes to infection. J Immunol 2000, 164:3713-3722

62. Ghassabeh GH, De Baetselier P, Brys L, Noel W, Van Ginderachter JA, Meerschaut S, Beschin A, Brombacher F, Raes G: Identification of a common gene signature for type II cytokine-associated myeloid cells elicited in vivo in different pathologic conditions. Blood 2006, 108:575-583

63. Martinez FO, Sica A, Mantovani A, Locati M: Macrophage activation and polarization. Front Biosci 2008, 13:453-461

64. Nelson MP, Christmann BS, Werner JL, Metz AE, Trevor JL, Lowell CA, Steele C: IL-33 and M2a alveolar macrophages promote lung defense against the atypical fungal pathogen Pneumocystis murina. J Immunol 2011, 186:2372-2381

65. Girard D, Paquin R, Naccache PH, Beaulieu AD: Effects of interleukin-13 on human neutrophil functions. J Leukoc Biol 1996, 59:412-419

66. Shim JJ, Dabbagh K, Ueki IF, Dao-Pick T, Burgel PR, Takeyama K, Tam DC, Nadel JA: IL-13 induces mucin production by stimulating epidermal growth factor receptors and by activating neutrophils. Am J Physiol Lung Cell Mol Physiol 2001, 280:L134-L140

67. Olszewski MA, Falkowski NR, Surana R, Sonstein J, Hartman A, Moore BB, Huffnagle GB, Toews GB: Effect of laparotomy on clearance and cytokine induction in Staphylococcus aureus infected lungs. Am J Respir Crit Care Med 2007, 176:921-929 